\title{
ON THE TRANSITION FROM REGULAR TO CHAOTIC BEHAVIORS IN THE TWO DEGREES OF FREEDOM DYNAMICAL SYSTEM
}

\author{
Nguyen Van Khang and Nguyen Hoang Duong \\ Hanoi University of Technology
}

\begin{abstract}
The main objective of the present paper is to study the transition from periodic regular motion to chaos in a two degrees of freedom dynamical system by changing control parameters. The nonlinear differential equations governing motion of the system are derived from the Lagrange equations. By use of the Poincare map, the dynamical behavior is identified based on numerical solutions of the ordinary differential equations. The Lyapunov exponent and the frequency spectrum are calculated to identify chaos. From numerical simulations, it is indicated that the periodic, quasi-periodic and chaotic motions occur in the considered system.
\end{abstract}

\section{INTRODUCTION}

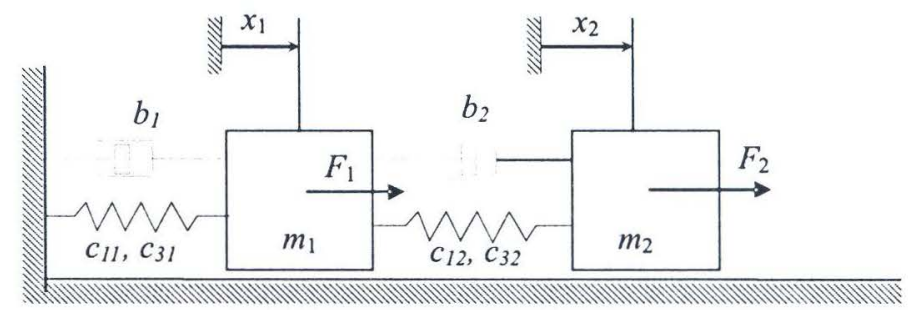

Fig. 1. Mechanical model

In recent years, the study of chaotic behaviors and strange attractors in deterministic nonlinear systems has undoubtedly developed into one of the main topics in the study of nonlinear phenomena in dynamical systems performed by engineers and applied scientists [1-10]. Many important and interesting applications are found in nonlinear oscillations, which does not come as a surprise since nowadays the classical methods of solution for such nonlinear problems are well known, and also since the new and rather abstract mathematical tools arise in a rather natural way in nonlinear oscillations. Much interest has been devoted to the study of chaos in nonlinear oscillators of the Duffing type [1, 7 , 8], Mathieu type $[1,12,13]$ and Van der Pol type $[7,10,15,16]$.

Let us consider here the two-degree-of-freedom dynamical system (Fig. 1). It is a system with connects the Duffing and the linear oscillators. 
This dynamical system is described by Lagrange's equations

$$
\begin{gathered}
m_{1} \ddot{x}_{1}+\left(b_{1}+b_{2}\right) \dot{x}_{1}+\left(c_{11}+c_{12}\right) x_{1}+c_{31} x_{1}^{3}-b_{2} \dot{x}_{2}-c_{12} x_{2}+c_{31}\left(x_{2}-x_{1}\right)^{3}=B_{1} \cos (\Omega t) \\
m_{2} \ddot{x}_{2}-b_{2} \dot{x}_{1}-c_{12} x_{1}+b_{2} \dot{x}_{2}+c_{12} x_{2}+c_{32}\left(x_{2}-x_{1}\right)^{3}=B_{2} \cos (\Omega t)
\end{gathered}
$$

where $B_{1}$ and $B_{2}$ are the amplitudes of the excitation forces, and $\Omega$ its frequency. Changing a control parameter $B_{i}(\mathrm{i}=1,2)$ it is possible to obtain the transition from periodic motion to chaos. In reference [17] J. Szopa studied the influence of chaotic vibrations of the Duffing part of this system on the linear part in the case $B_{1} \neq 0, B_{2}=0$. In this paper the numerical simulation is used to study the transition from regular periodic motion to chaotic behaviors in the two degrees of freedom Duffing system. For the numerical analysis it has been assumed that $m_{1}=m_{2}=1 \mathrm{~kg}, c_{11}=0, c_{31}=1 \mathrm{~N} / \mathrm{m}^{3}, c_{12}=1 \mathrm{~N} / \mathrm{m}, c_{32}=0$, $\Omega=1 \mathrm{rad} / \mathrm{s}, b_{1}=b_{2}=0.05 \mathrm{Ns} / \mathrm{m}$.

\section{TRANSITION FROM PERIODIC MOTION TO CHAOS BY CHANGING THE CONTROL FORCE $B_{1},\left(B_{2}=0\right)$}

The characteristics of chaos which were used in the investigations are the following: non-regular displacement, non-existence of limit cycles in phase plane, shape of the Poincare map, wide frequency spectrum.

\subsection{Control force $B_{1}=12, B_{2}=0$}

The Figs. 2a-2h show the regular periodic motion for $B_{1}=12$. The Figs. $2 \mathrm{a}$ and 2e present the displacement of $x_{1}$ and $x_{2}$. The trajectories in phase plane are shown in Figs. $2 \mathrm{~b}$ and $2 \mathrm{f}$. The Poincare maps are presented in Figs. $2 \mathrm{c}$ and $2 \mathrm{~g}$. Two points in Poincare maps of nonautonomous systems indicate that the period of oscillations is cqual to twice as the period of the excitation force $T_{O}=2 \pi / \Omega[4,9]$. Figs. $2 \mathrm{~d}$ and $2 \mathrm{~h}$ present the frequency spectrum. As it can be seen from the largest Lyapunov exponents map in Fig. 2i, the largest Lyapunov exponents for this case are always negative.

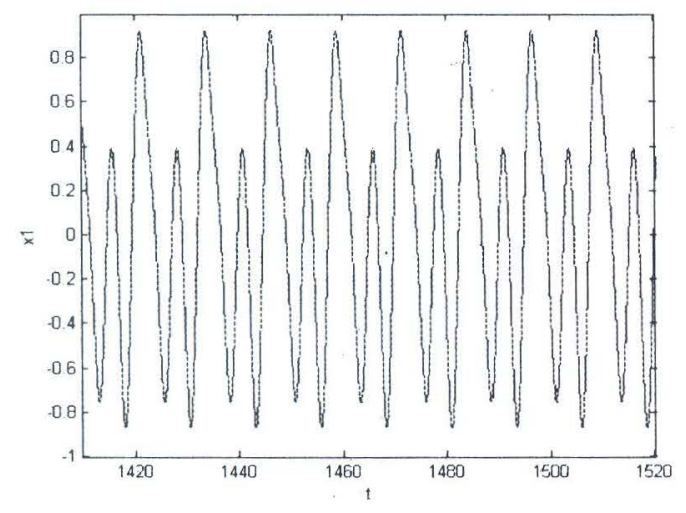

Fig. 2a. Displacement of $x_{1}$

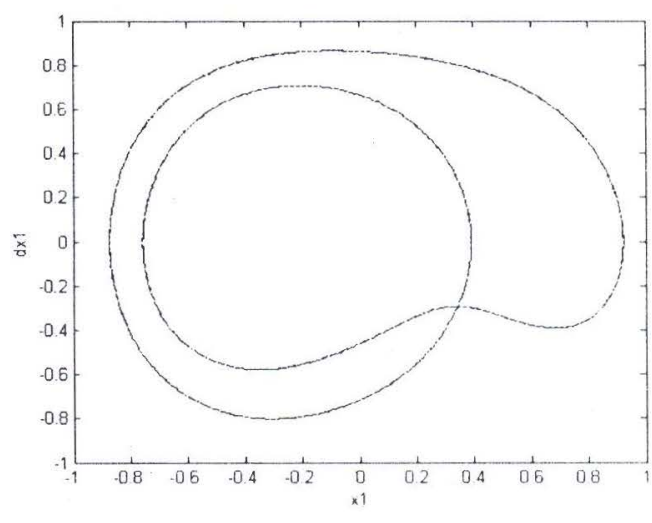

Fig. 2b. Phase orbit 


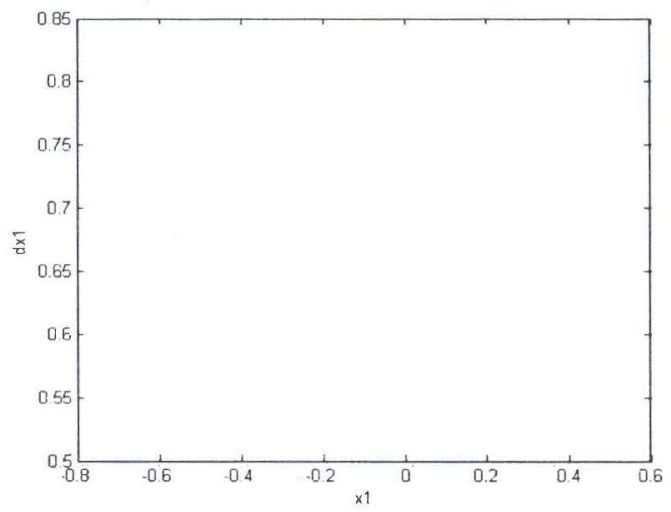

Fig. 2c. Poincare map

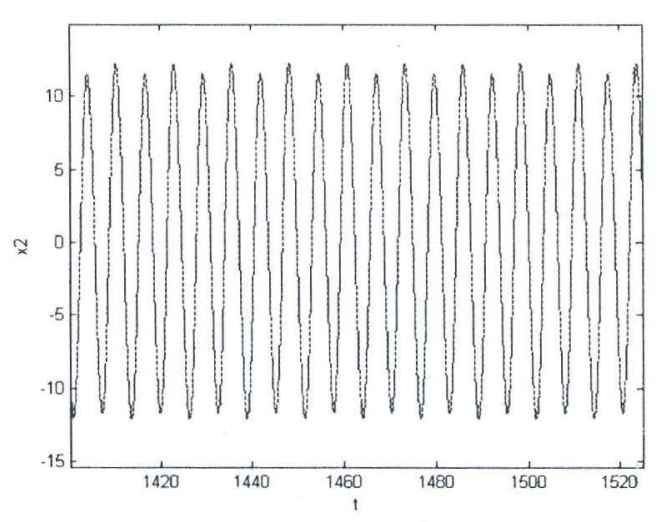

Fig. 2e. Displacement of $x_{2}$

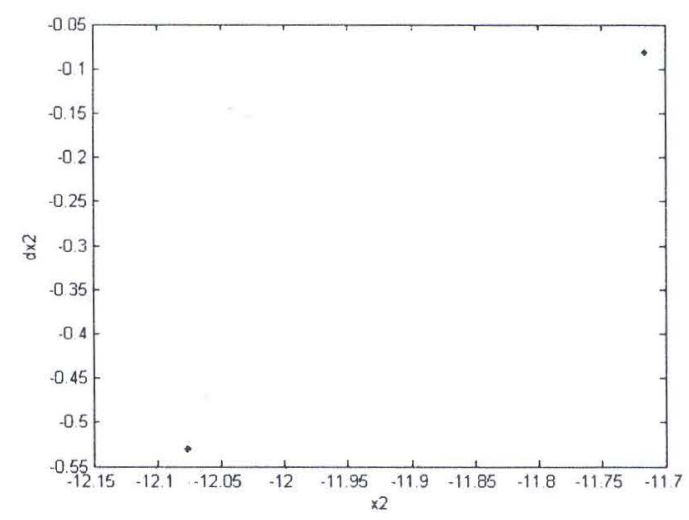

Fig. 2g. Poincare map

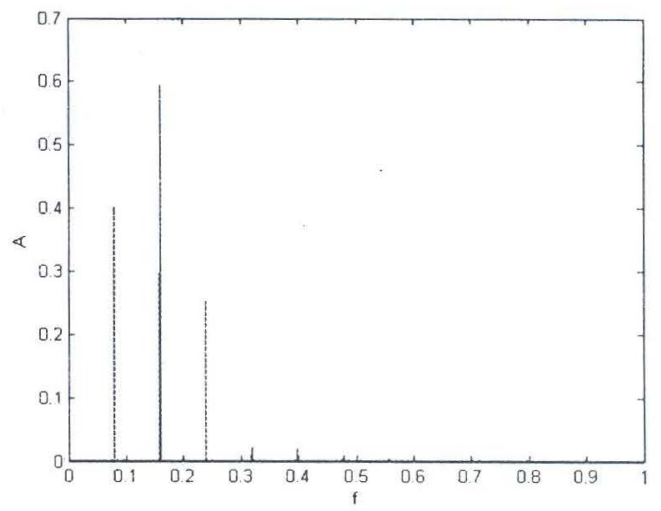

Fig. 2d. Frequency spectrum

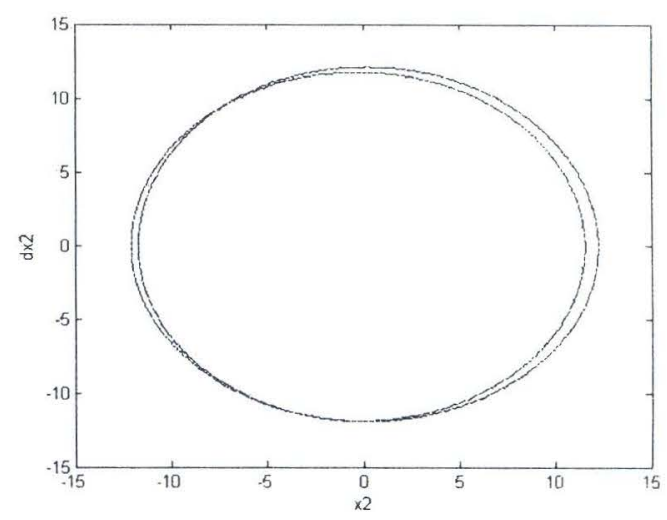

Fig. 2f. Phase orbit

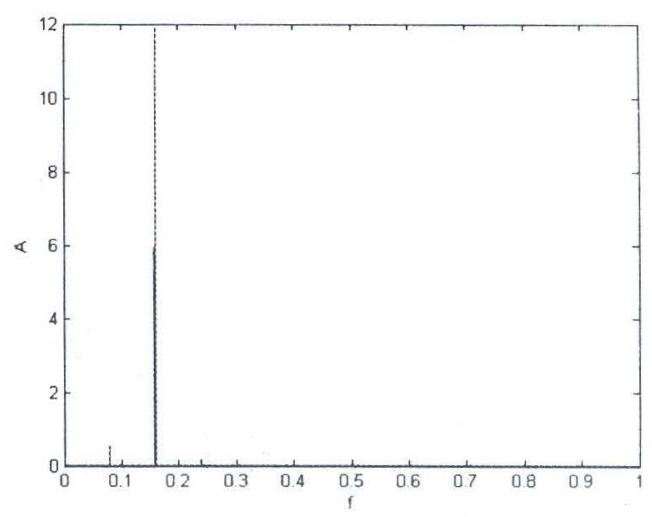

Fig. 2h. Frequency spectrum 


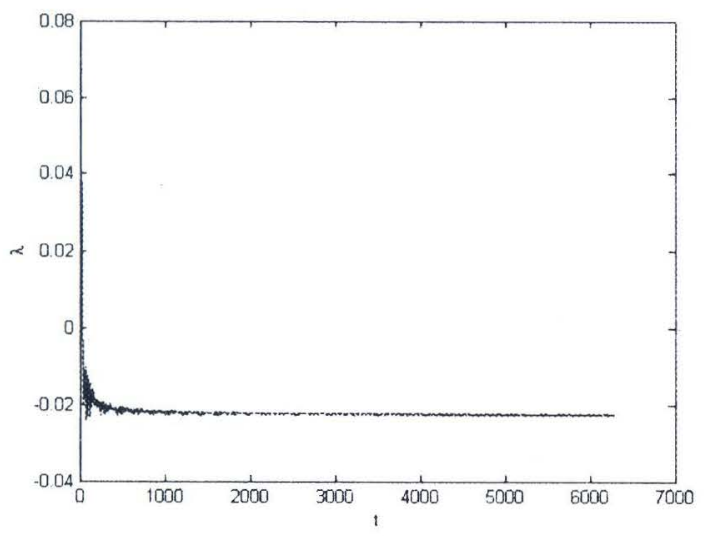

Fig. 2i. Lagest Lyapunov exponent

\subsection{Control force $B_{1}=12.2, \quad B_{2}=0$}

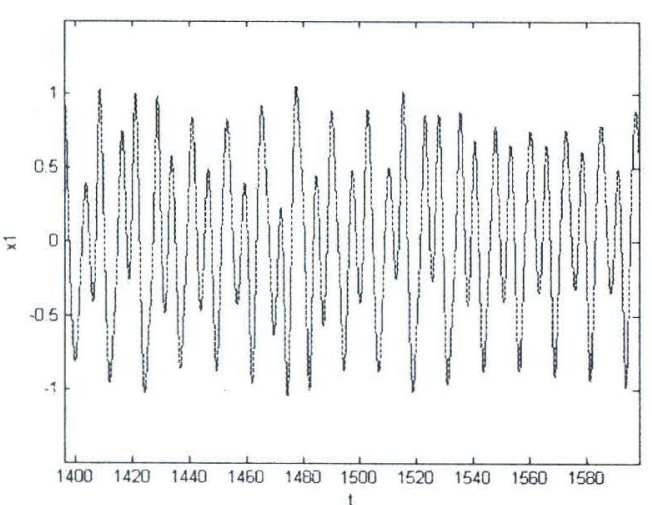

Fig. 3a. Displacement of $x_{1}$

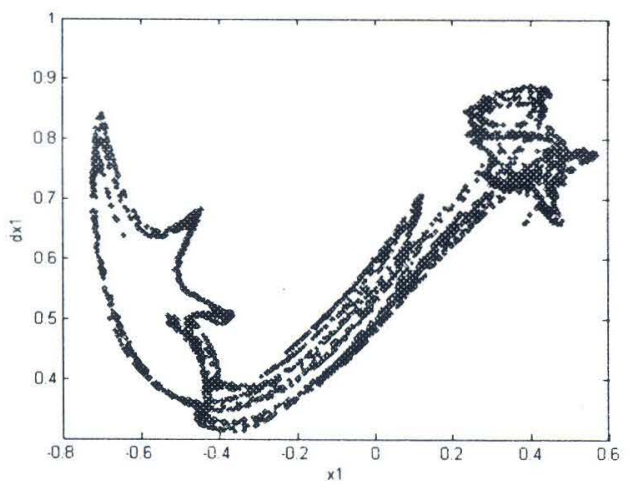

Fig. 3c. Poincare map

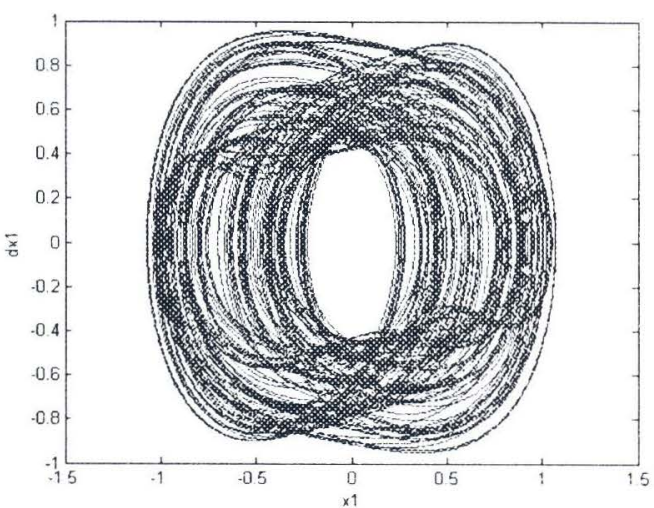

Fig. 36. Phase orbit

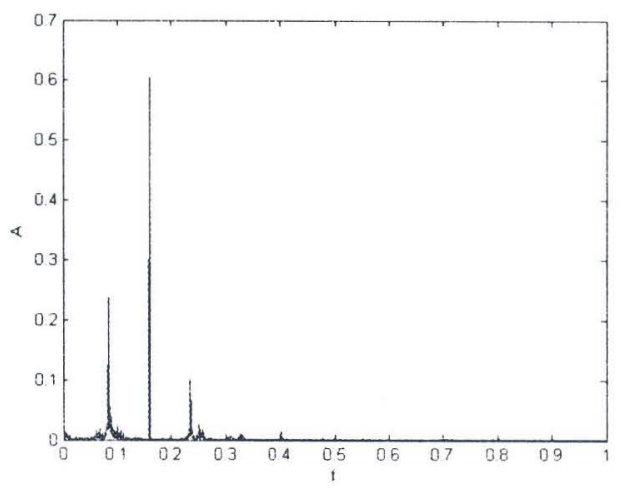

Fig. 3d. Frequency spectrum 


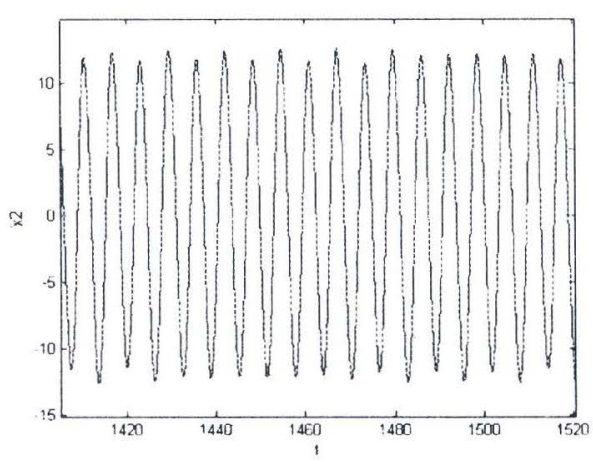

Fig. 3e. Displacement of $x_{2}$

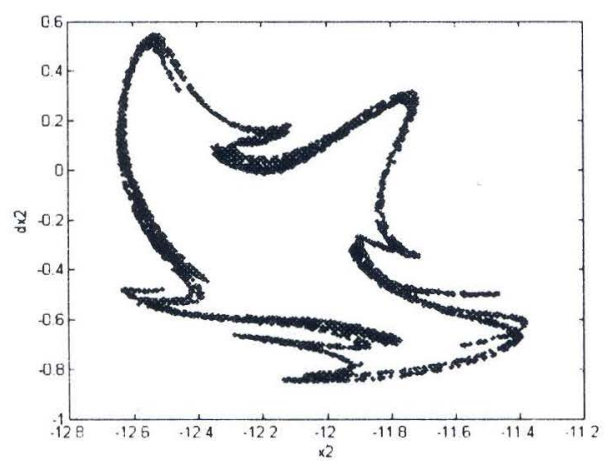

Fig. 3g. Poincare map

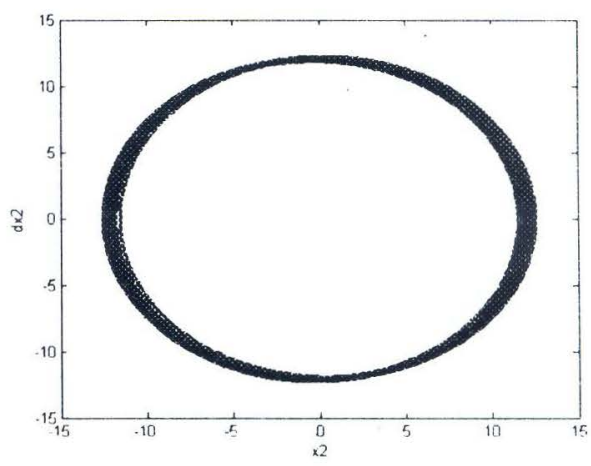

Fig. 3f. Phase orbit

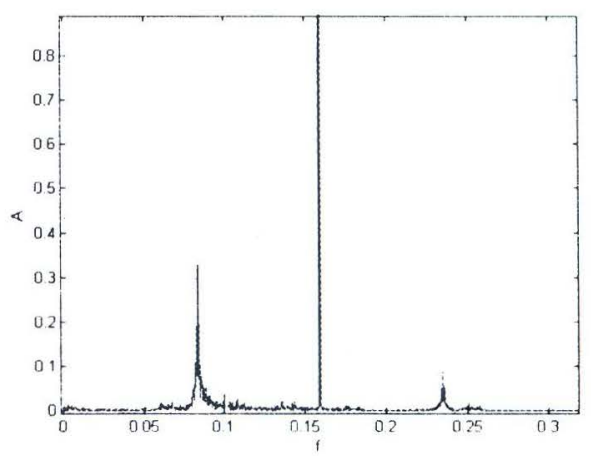

Fig. 3h. Frequency spectrum

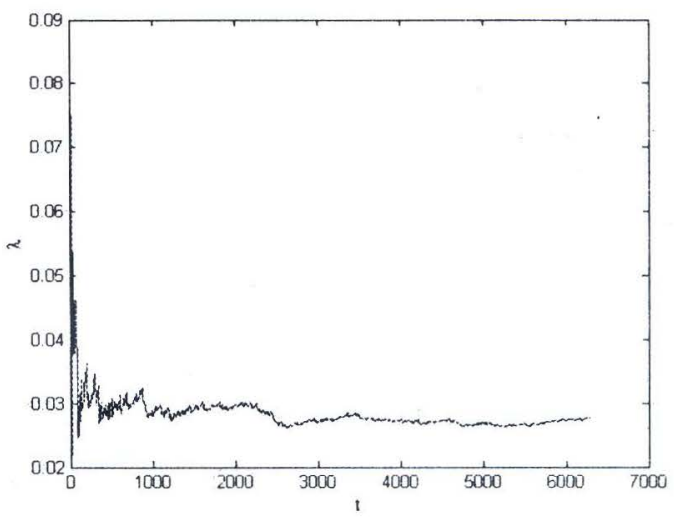

Fig. 3i. Lagest Lyapunov exponent 
The Figs. 3a-3h show the characteristics of chaos for $B_{1}=12.2$. The Figs. 3a and 3e present the displacement of $x_{1}$ and $x_{2}$. The trajectories in phase plane are shown in Figs. $3 \mathrm{~b}$ and $3 \mathrm{f}$. The Poincare maps are presented in Figs. 3c and 3g. Figs. 3d and 3h present the frequency spectrum. As it can be seen from the largest Lyapunov exponents map in Fig. 3i, the largest Lyapunov exponent for this case are always positive.

\subsection{Control force $B_{1}=18, \quad B_{2}=0$}

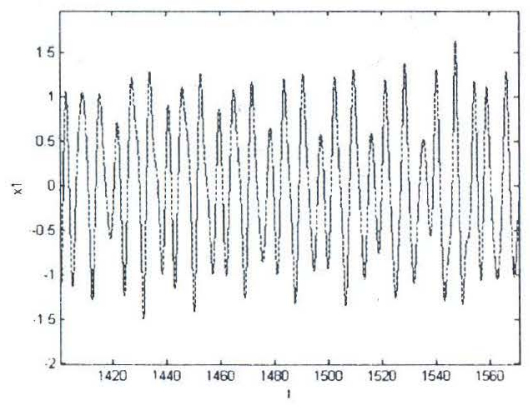

Fig. 4a. Displacement of $x_{1}$

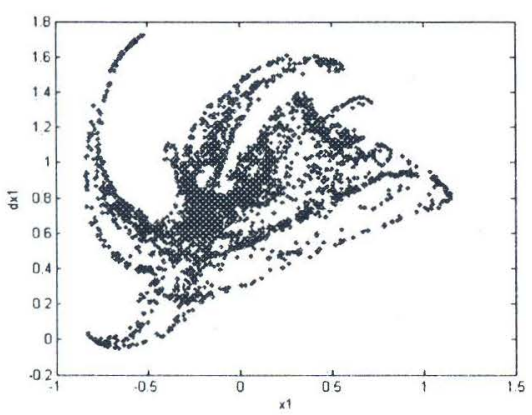

Fig. 4c. Poincare map

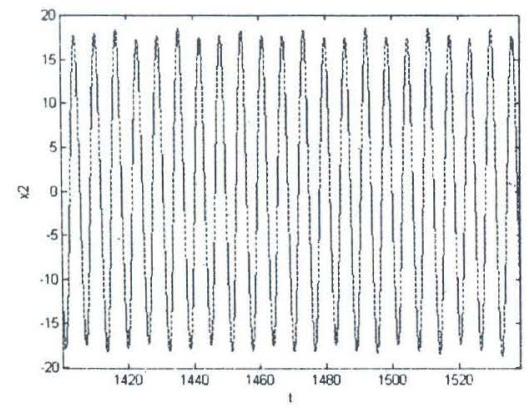

Fig. 4e. Displacement of $x_{2}$

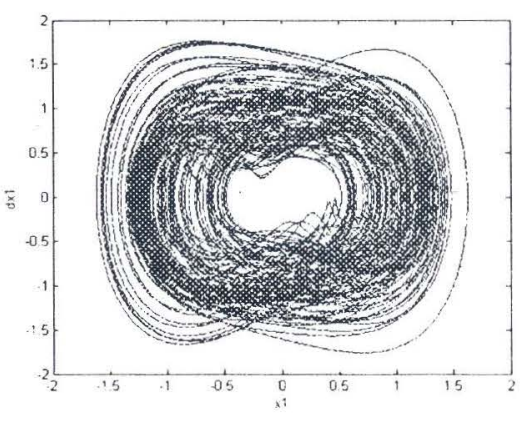

Fig. 4b. Phase orbit

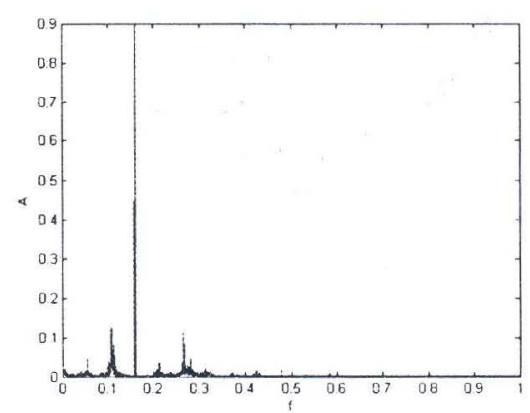

Fig. 4d. Frequency spectrum

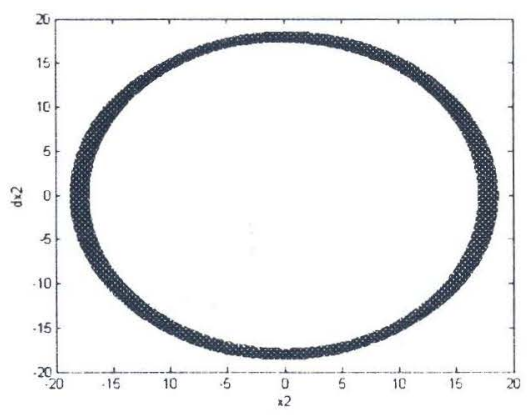

Fig. 4f. Phase orbit 


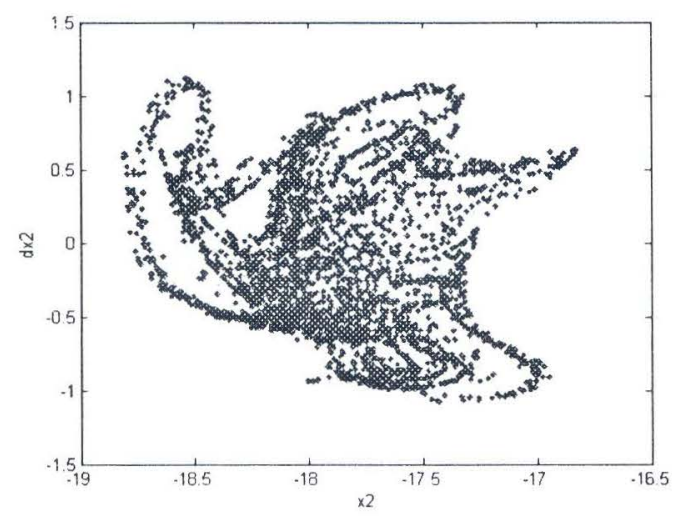

Fig. 4g. Poincare map

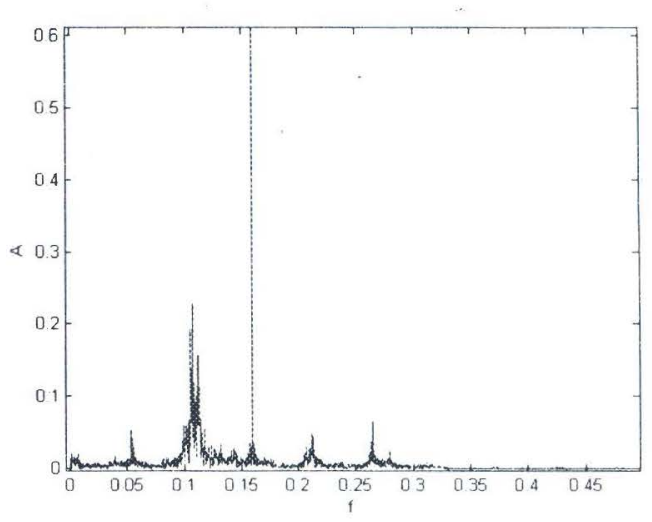

Fig. 4h. Frequency spectrum

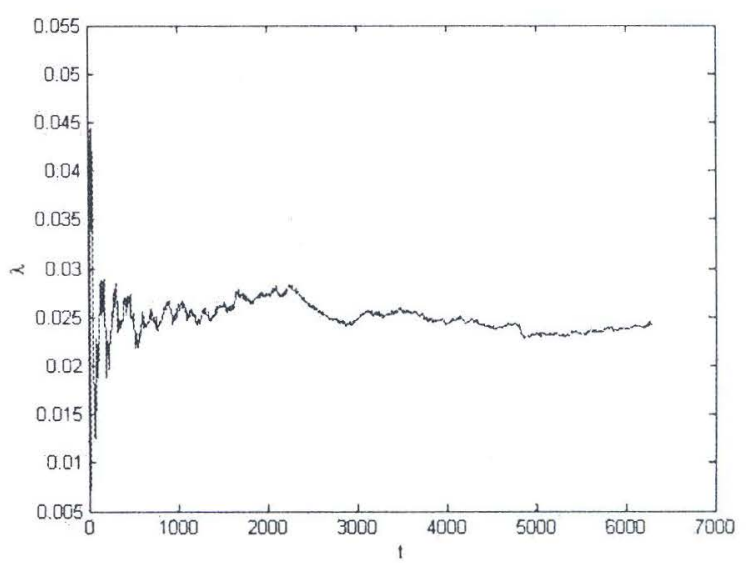

Fig. 4i. Lagest Lyapunov exponent

The Figs. $4 \mathrm{a}-4 \mathrm{~h}$ show the characteristics of chaos for $B_{1}=19$. The Figs. $4 \mathrm{a}$ and $4 \mathrm{e}$ present the displacement of $x_{1}$ and $x_{2}$. The trajectories in phase plane are shown in Figs. $4 \mathrm{~b}$ and $4 \mathrm{f}$. The Poincare maps are presented in Figs. 4c and 4g. Figs. 4d and $4 \mathrm{~h}$ present the frequency spectrum. As it can be seen from the largest Lyapunov exponent map in Fig. 4i, the largest Lyapunov exponents for this case are always positive.

\subsection{Control force $B_{1}=19, B_{2}=0$}

The Figs. 5a-5h show the characteristics of chaos for $B_{1}=19$. The Figs. $5 \mathrm{a}$ and $5 \mathrm{e}$ present the displacement of $x_{1}$ and $x_{2}$. The trajectories in phase plane are shown in Figs. $5 \mathrm{~b}$ and $5 \mathrm{f}$. The Poincare maps are presented in Figs. 5c and 5g. Figs. 5d and 5h present the frequency spectrum. As it can be seen from the largest Lyapunov exponent map in Fig. 5i, the largest Lyapunov exponents for this case are always positive. 


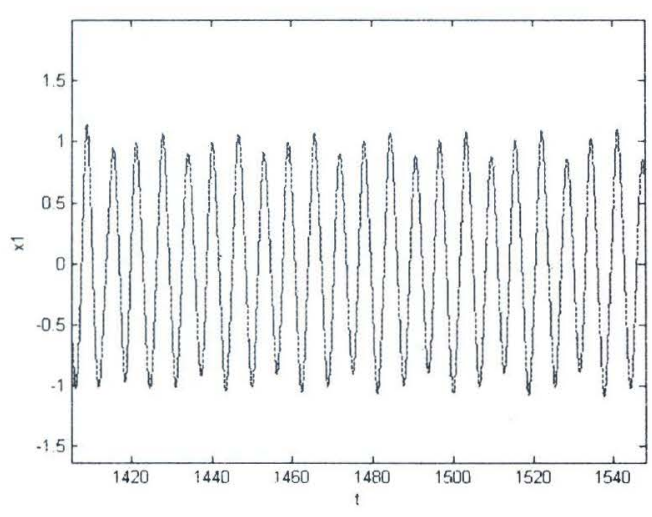

Fig. 5a. Displacement of $x_{1}$

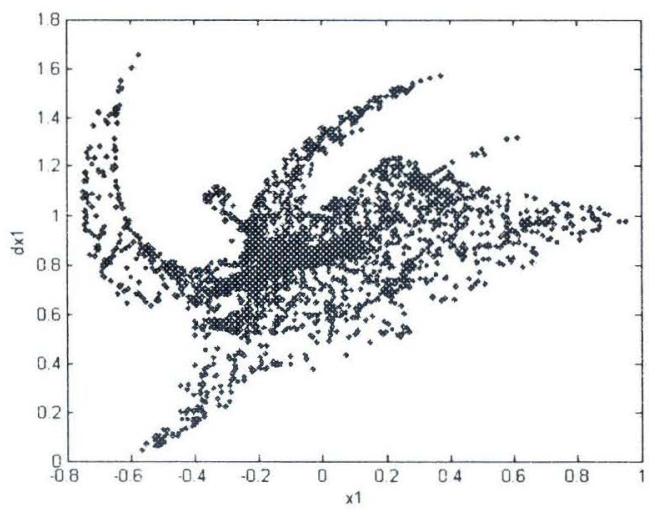

Fig. 5c. Poincare map

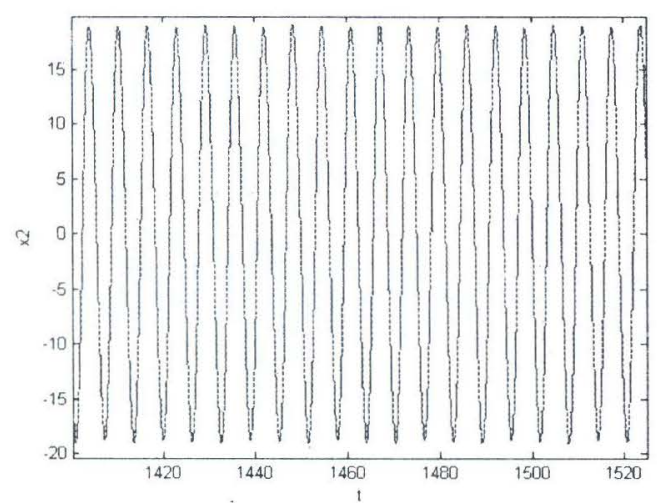

Fig. 5e. Displacement of $x_{2}$

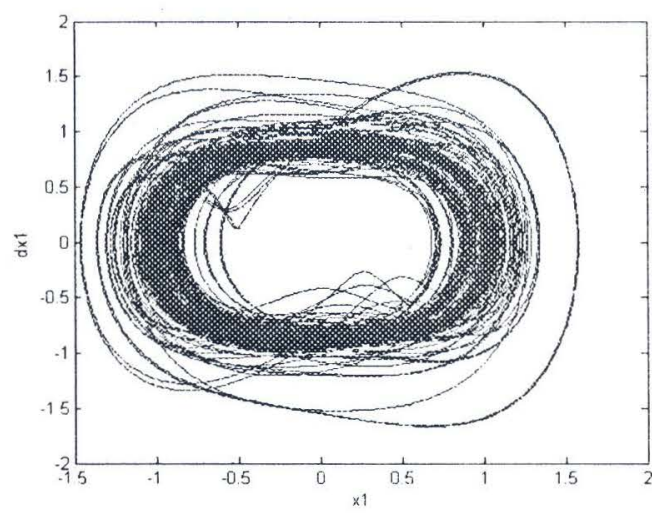

Fig. 5b. Phase orbit

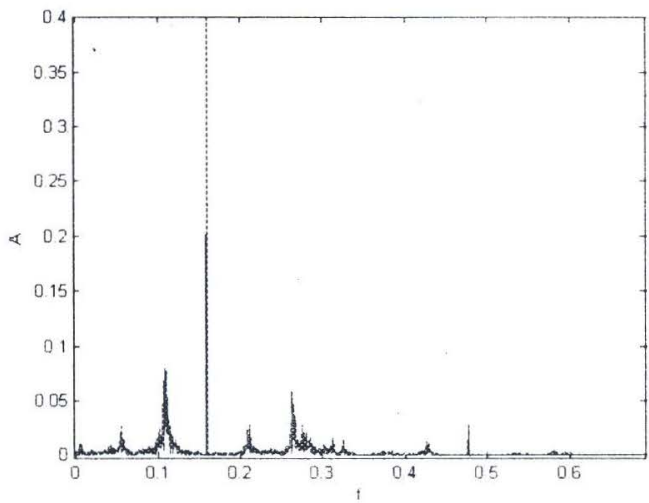

Fig. 5d. Frequency spectrum

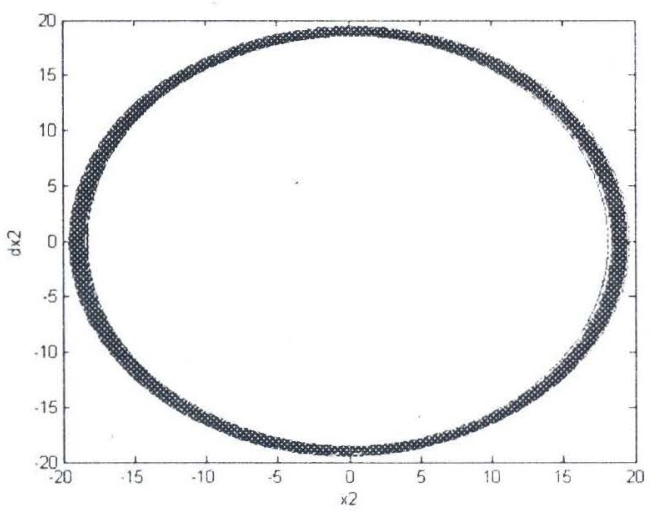

Fig. 5f. Phase orbit 


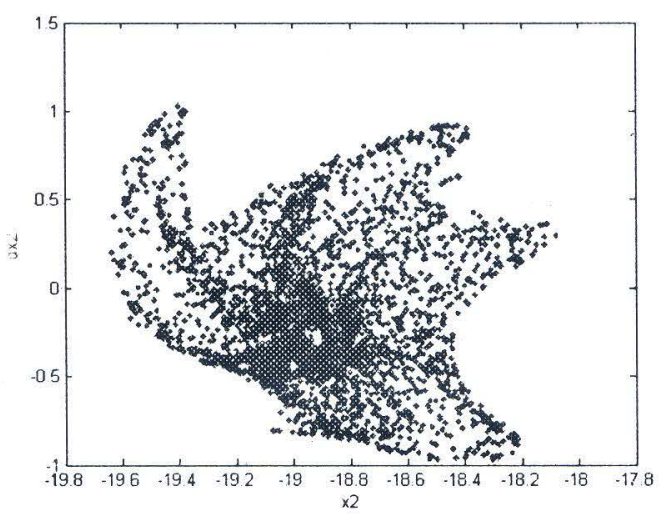

Fig. 5g. Poincare map

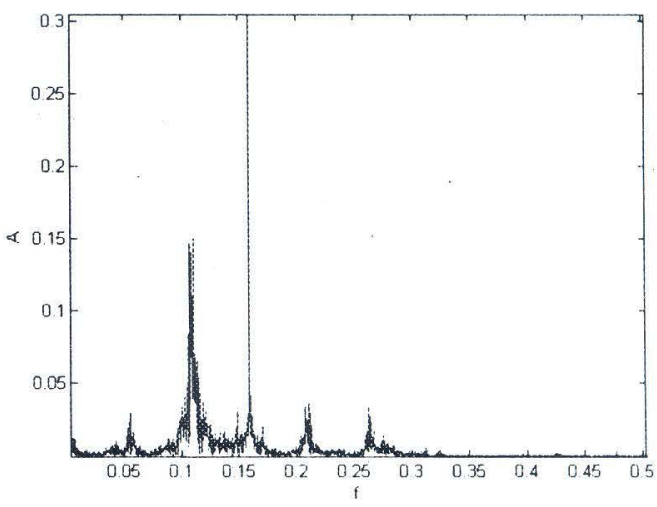

Fig. 5h. Frequency spectrum

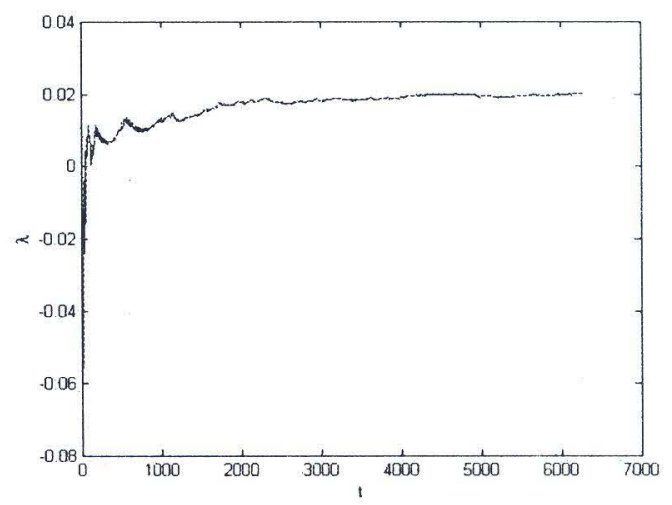

Fig. 5i. Lagest Lyapunov exponent

2.5. Control force $B_{1}=20, B_{2}=0$

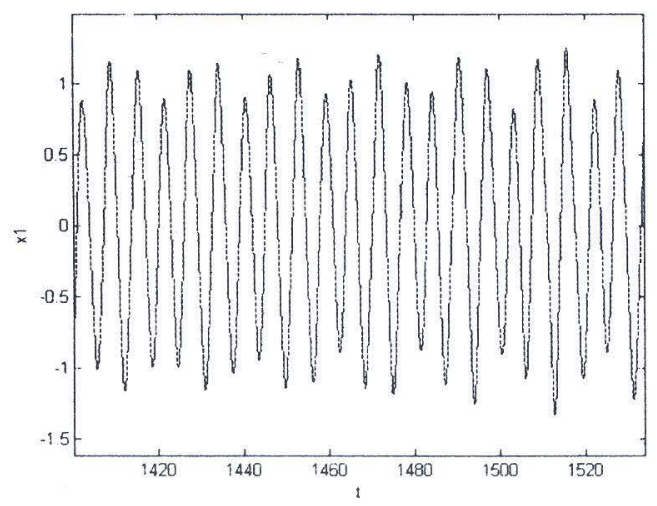

Fig. 6a. Displacement of $x_{1}$

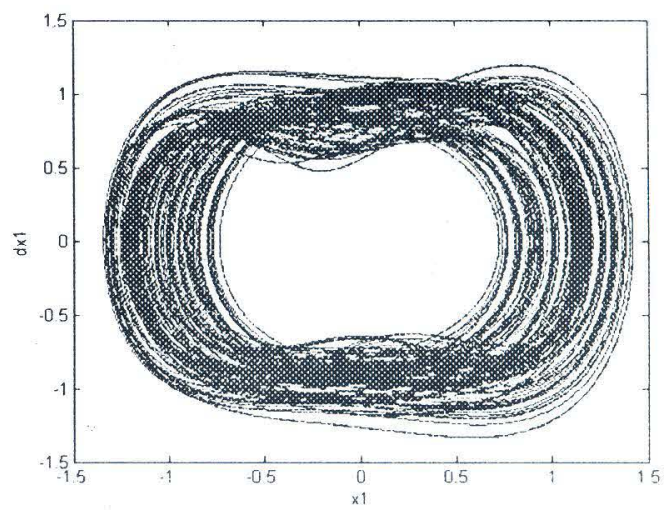

Fig. 6b. Phase orbit 


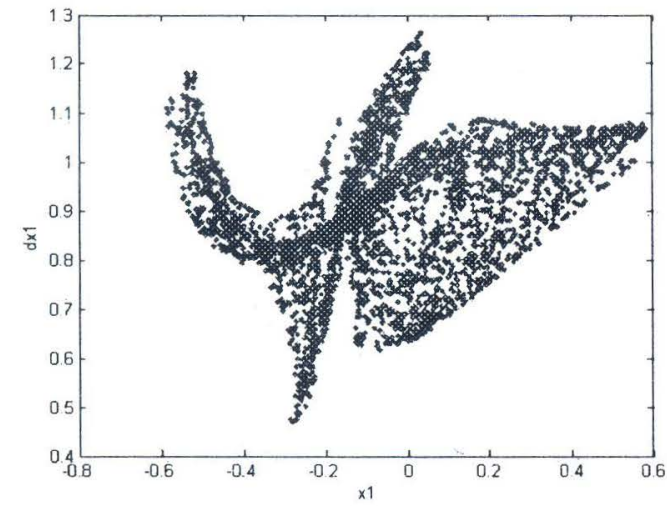

Fig. 6c. Poincare map

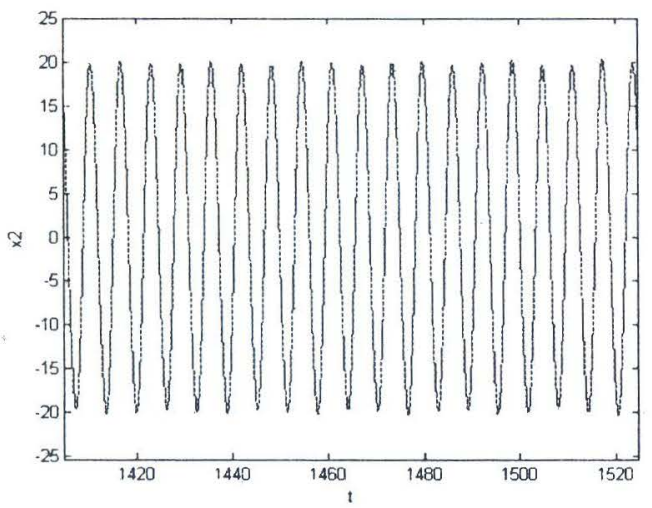

Fig. 6e. Displacement of $x_{2}$

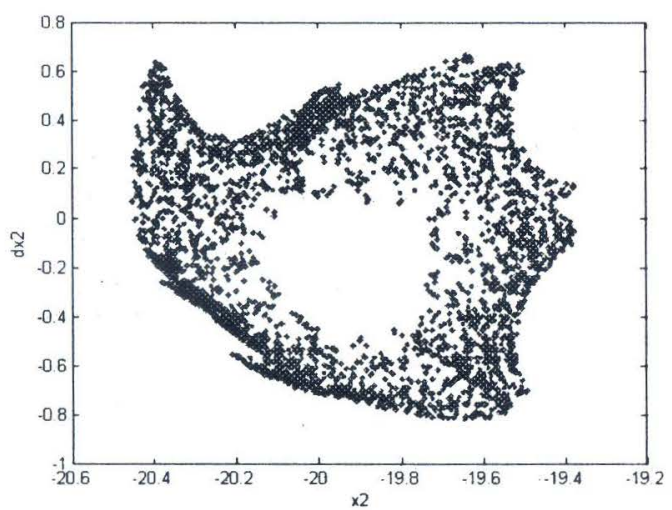

Fig. 6g. Poincare map

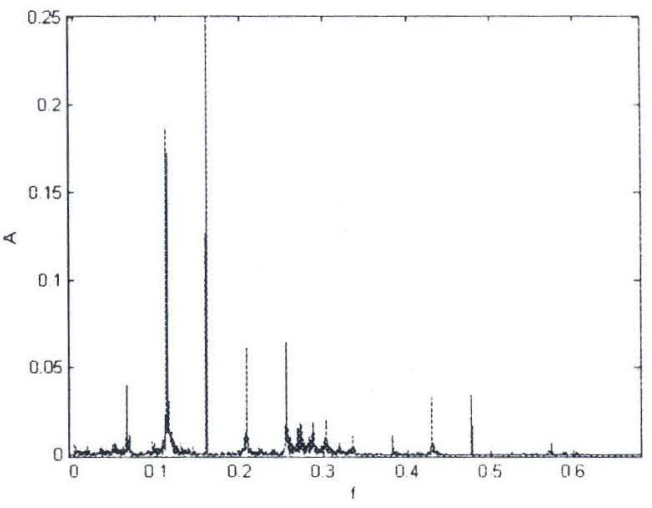

Fig. 6d. Frequency spectrum

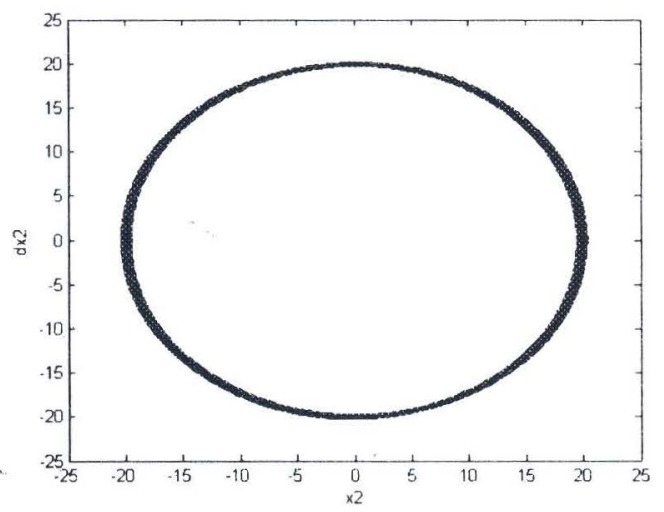

Fig. 6f. Phase orbit

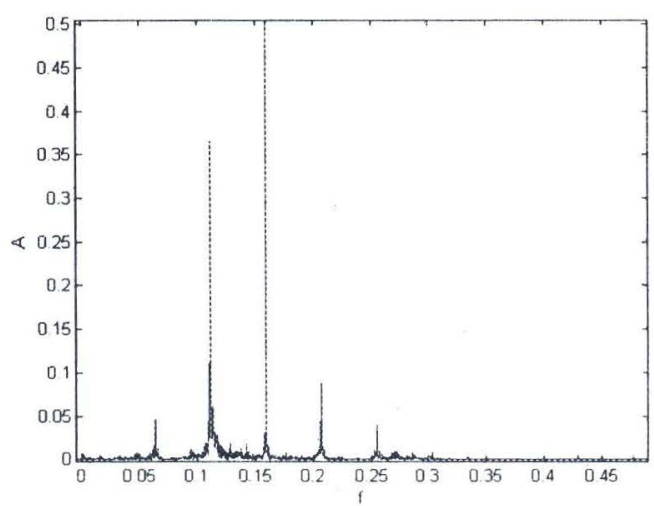

Fig. 6h. Frequency spectrum 


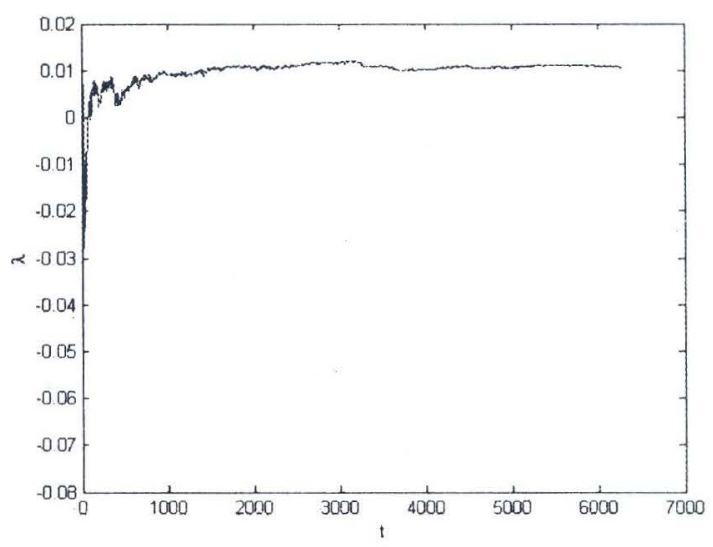

Fig. 6i. Lagest Lyapunov exponent

The Figs. 6a-6h show the characteristics of chaos for $B_{1}=20$. The Figs. $6 \mathrm{a}$ and $6 \mathrm{e}$ present the displacement of $x_{1}$ and $x_{2}$. The trajectories in phase plane are shown in Figs. $6 \mathrm{~b}$ and $6 \mathrm{f}$. The Poincare maps are presented in Figs. 6c and 6g. Figs. 6d and 6h present the frequency spectrum. As it can be seen from the largest Lyapunov exponent map in Fig. 6i, the largest Lyapunov exponents for this case are always positive.

\section{TRANSITION FROM PERIODIC MOTION TO CHAOS BY CHANGING THE CONTROL FORCES $B_{1}$ AND $B_{2}$}

3.1. Control force $B_{1}=6, B_{2}=5$

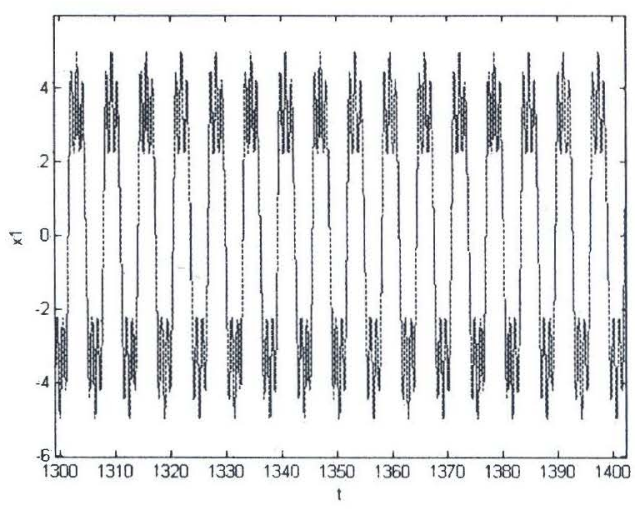

Fig. 7a. Displacement of $x_{1}$

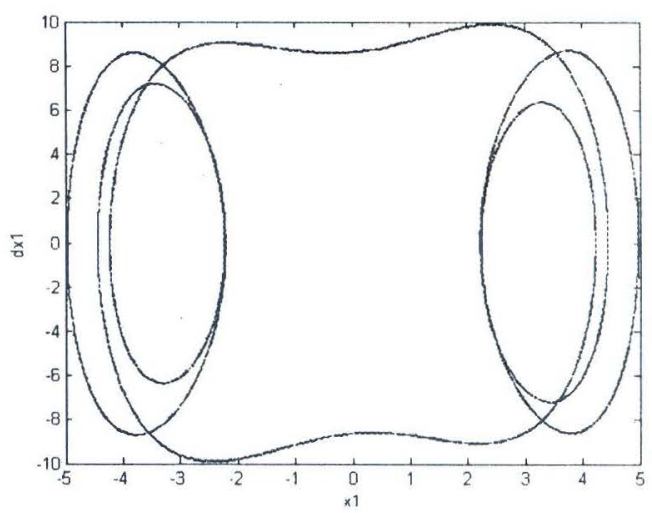

Fig. 7b. Phase orbit 


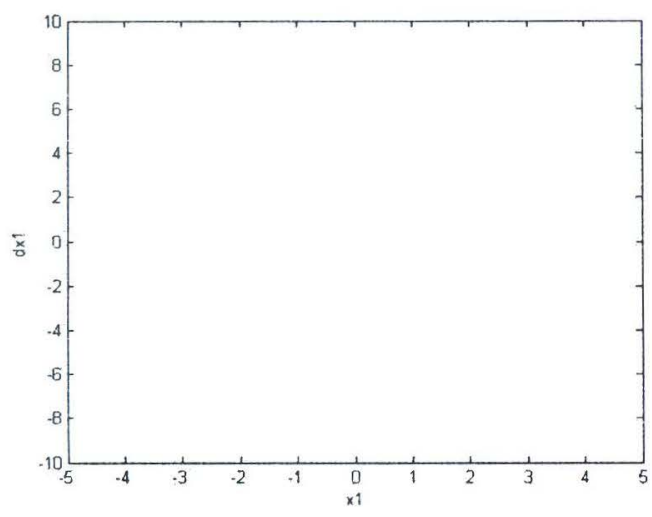

Fig. \%c. Poincare map

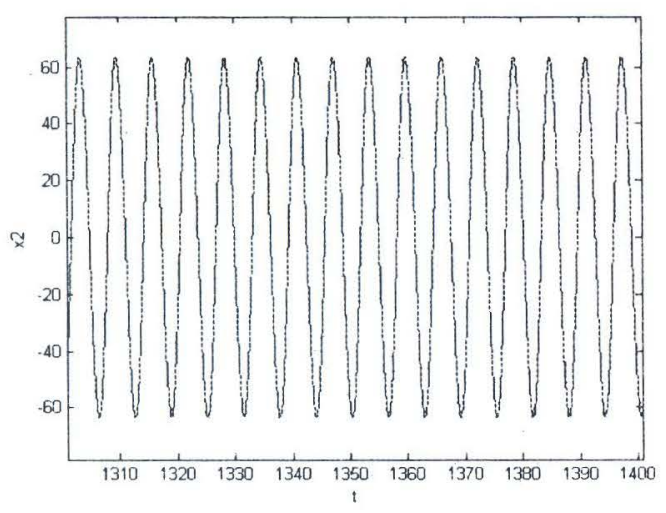

Fig. 7e. Displacement of $x_{2}$

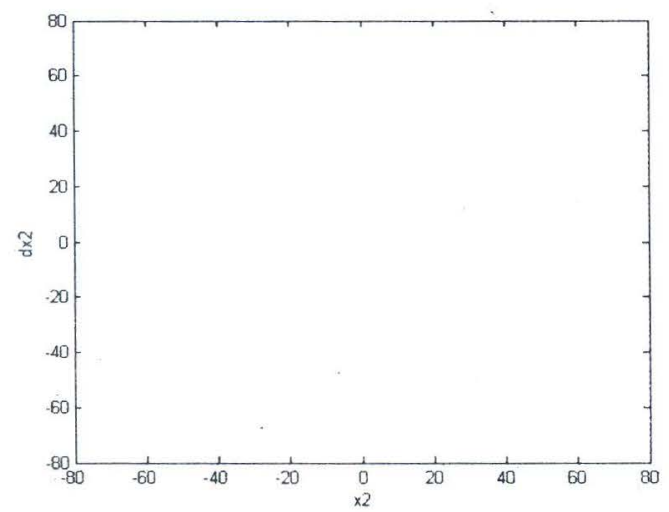

Fig. 7g. Poincare map

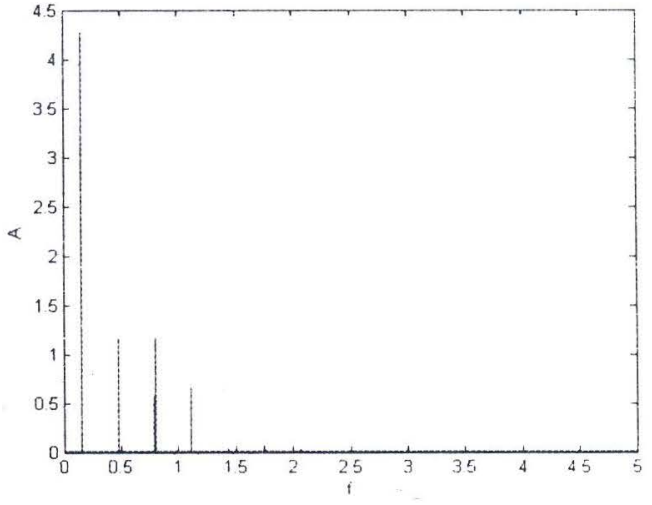

Fig. 7d. Frequency spectrum

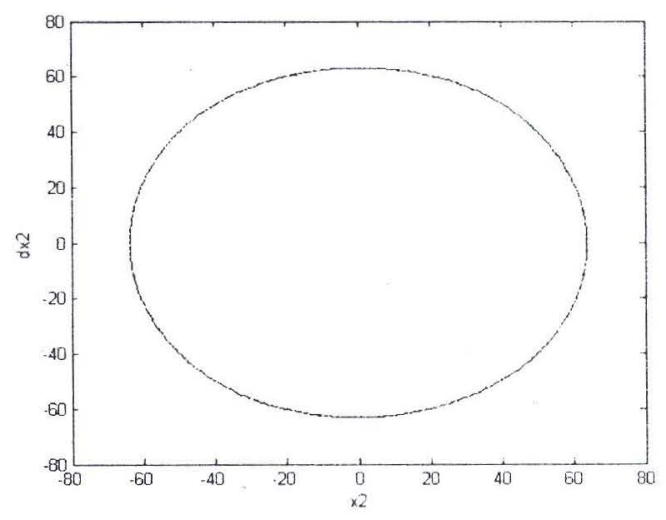

Fig. 7f. Phase orbit

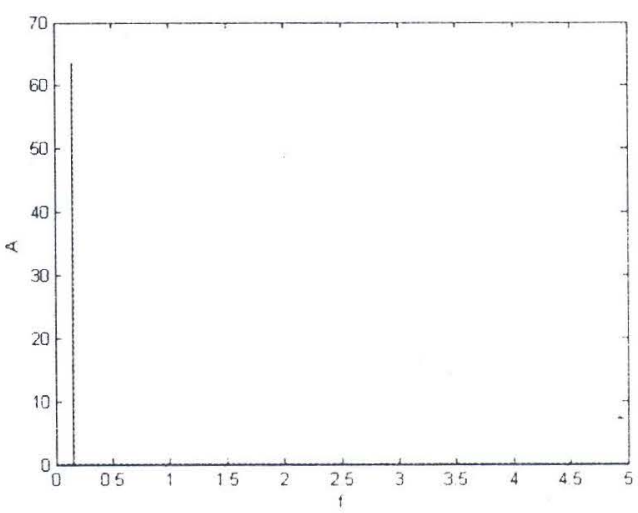

Fig. Th. Frequency spectrum 


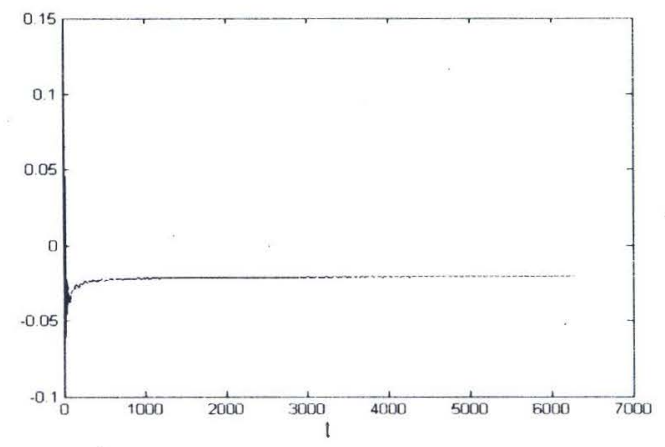

Fig. 7i. Lagest Lyapunov Exponent

The Figs. 7a-7h show the regular periodic motion for $B_{1}=6, B_{2}=5$. The Figs. $7 \mathrm{a}$ and $7 \mathrm{e}$ present the displacement of $x_{1}$ and $x_{2}$. The trajectories in phase plane are shown in Figs. 7b and 7f. The Poincare maps are presented in Figs. 7c and 7g. One point in Poincare maps of nonautonomous systems means that the period of oscillations is equal to a period of the excitation force $T_{O}=2 \pi / \Omega$. Figs. $7 \mathrm{~d}$ and 7 h present the frequency spectrum. As it can be seen from the largest Lyapunov exponent map in Fig. 7i, the largest Lyapunov exponents for this case are always negative

\subsection{Control force $B_{1}=6, B_{2}=2$}

The Figs. $8 \mathrm{a}-8 \mathrm{~h}$ show the characteristics of chaos for $B_{1}=6, B_{2}=2$. The Figs. $8 \mathrm{a}$ and $8 \mathrm{e}$ present the displacement of $x_{1}$ and $x_{2}$. The trajectories in phase plane are shown in Figs. 8b and 8f. The Poincare maps are presented in Figs. 8c and 8g. Figs. 8d and 8h present the frequency spectrum. As it can be seen from the largest Lyapunov exponent map in Fig. 8i, the largest Lyapunov exponents for this case are always positive.

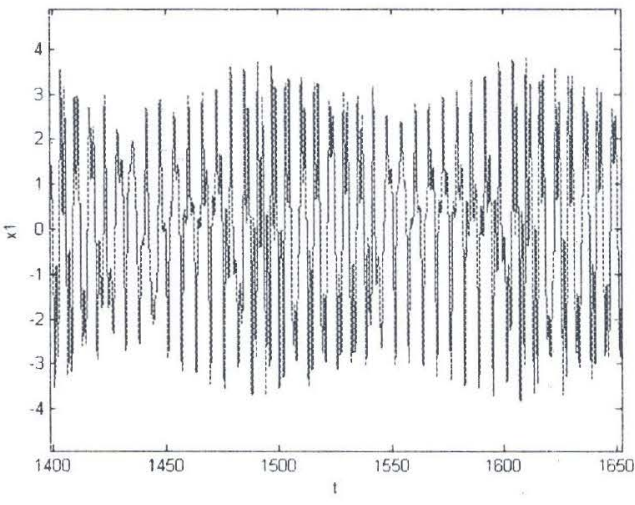

Fig. 8a. Displacement of $x_{1}$

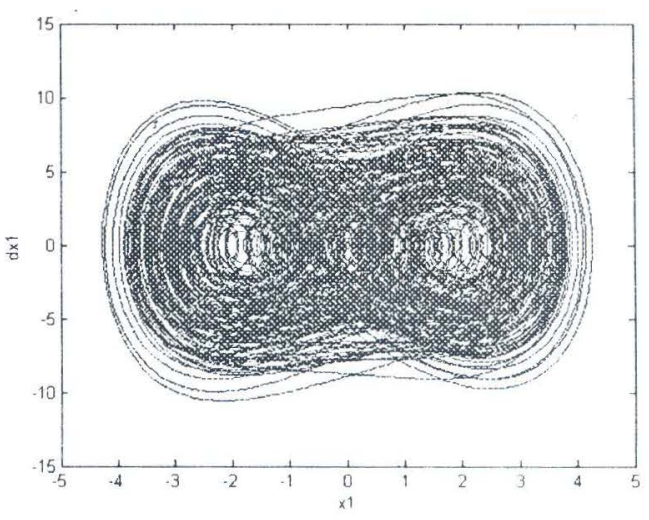

Fig. 8b. Phase orbit 


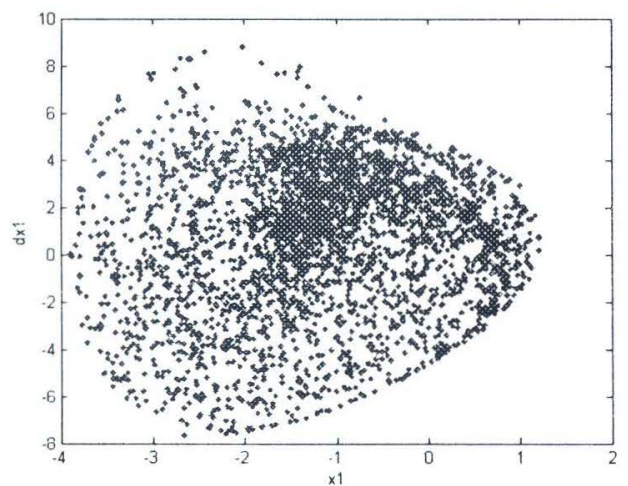

Fig. 8c. Poincare map

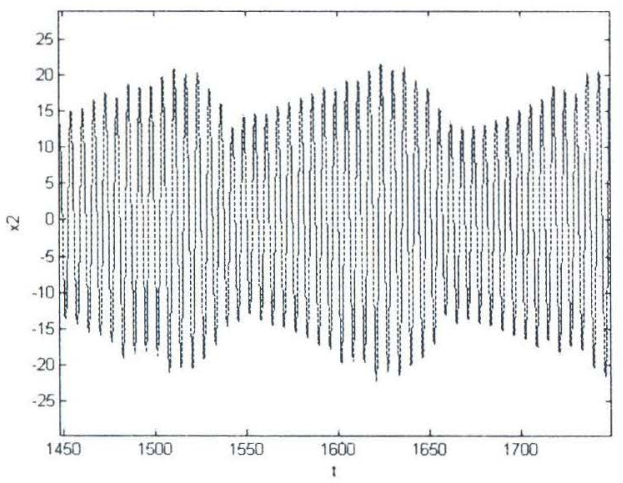

Fig. 8e. Displacement of $x_{2}$

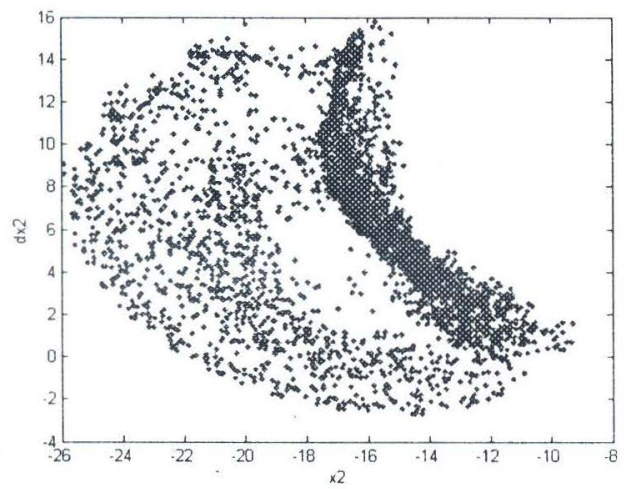

Fig. 8g. Poincare map

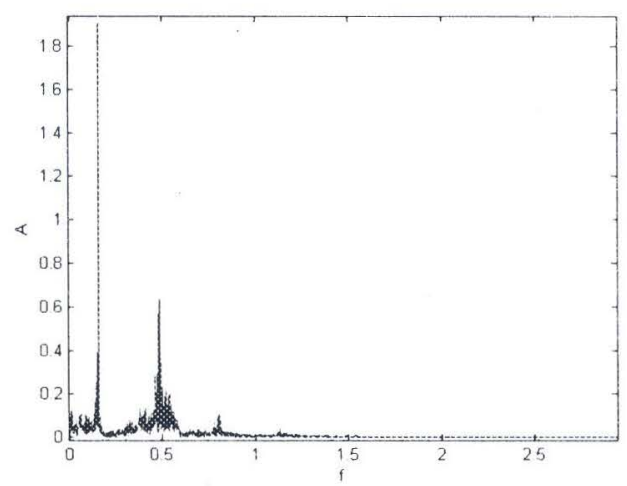

Fig. 8d. Frequency spectrum

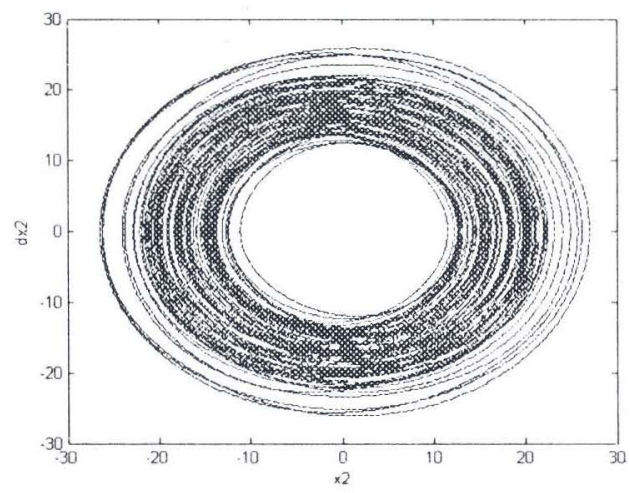

Fig. 8f. Phase orbit

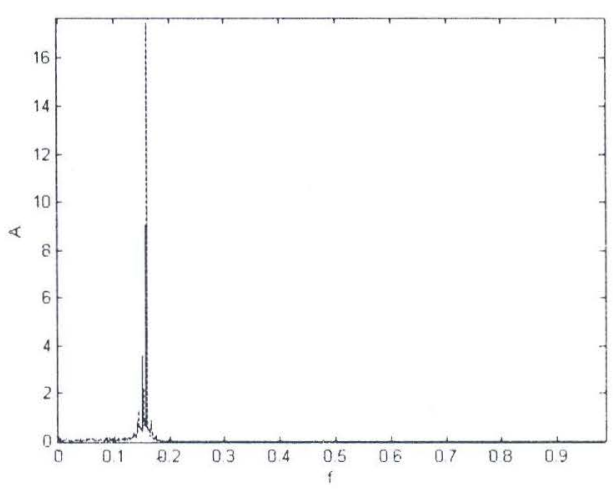

Fig. 8h. Frequency spectrum 


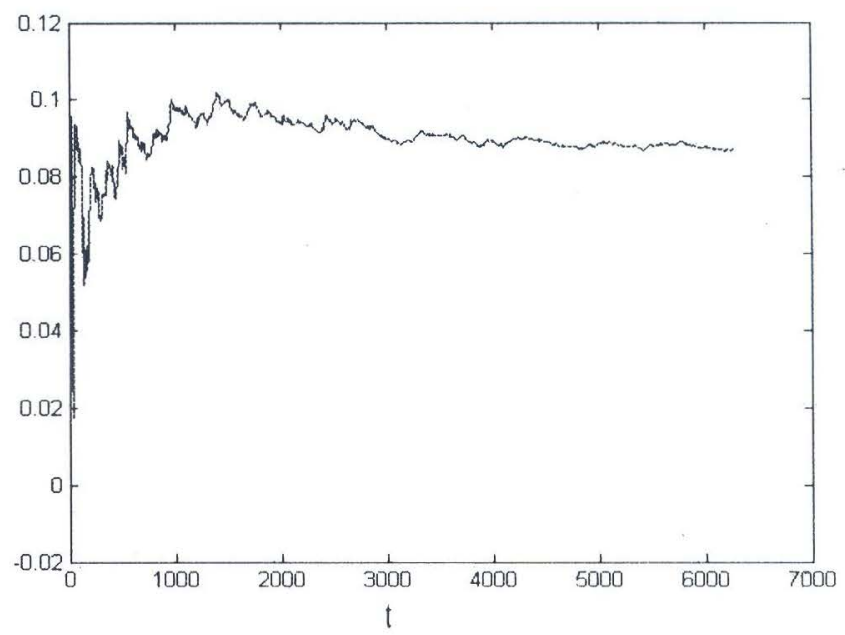

Fig. 8i. Lagest Lyapunov exponent

\subsection{Control force $B_{1}=12.2, B_{2}=5$}

The Figs. 9a-9h show the regular periodic motion for $B_{1}=6, B_{2}=5$. The Figs. $9 \mathrm{a}$ and $9 \mathrm{e}$ present the displacement of $x_{1}$ and $x_{2}$. The trajectories in phase plane are shown in Figs. 9b and 9f. The Poincare maps are presented in Figs. 9c and 9g. Figs. 9d and 9h present the frequency spectrum. As it can be seen from the largest Lyapunov exponent map in Fig. 9i, the largest Lyapunov exponents for this case are always negative.

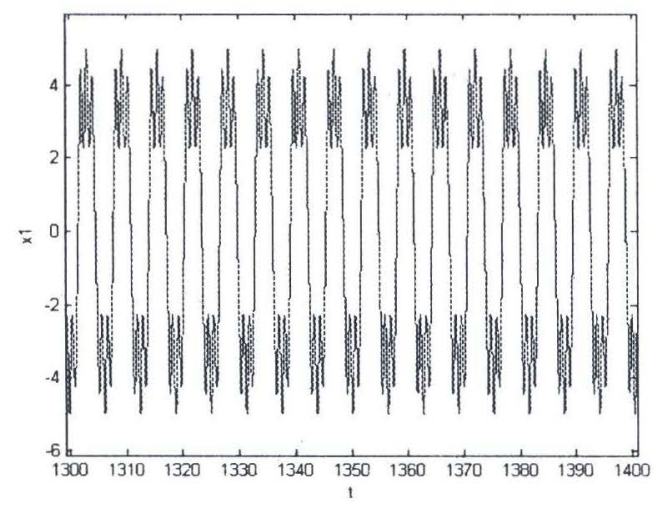

Fig. 9a. Displacement of $x_{1}$

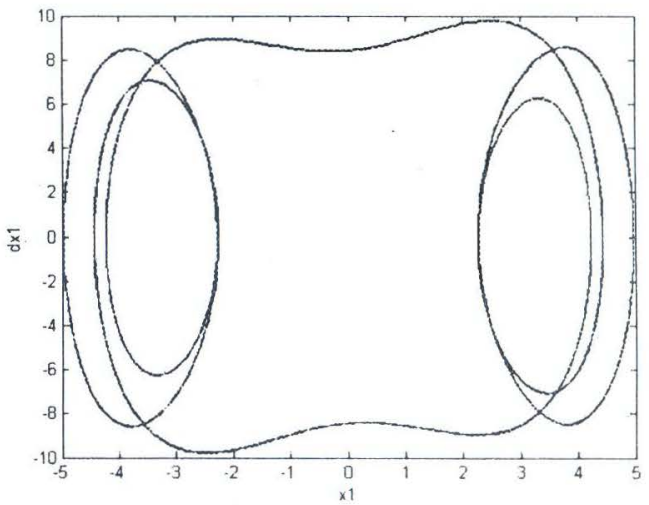

Fig. 9b. Phase orbit 


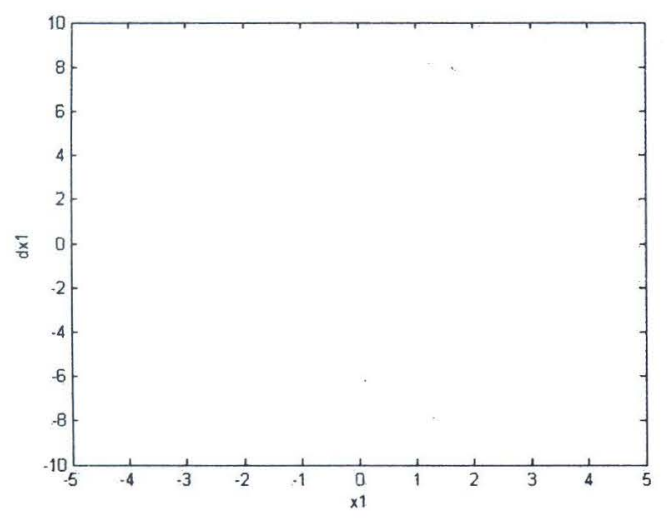

Fig. 9c. Poincare map

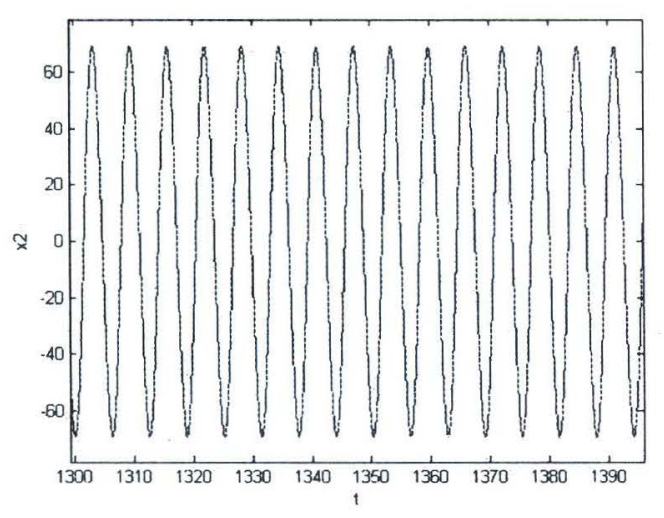

Fig. 9e. Displament of $x_{2}$

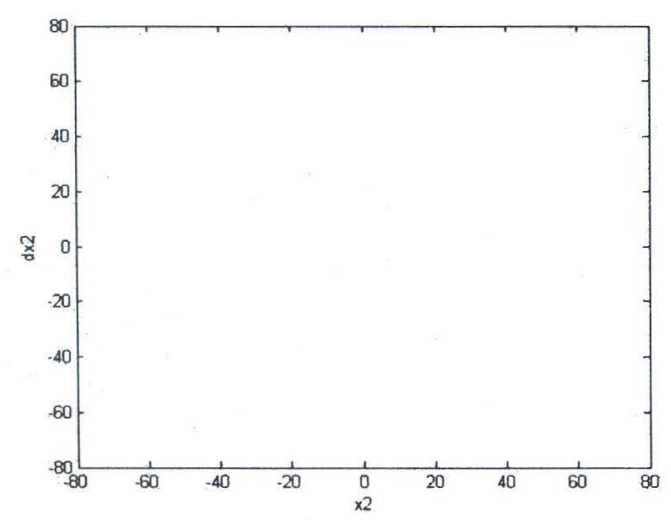

Fig. 9g. Poincare map

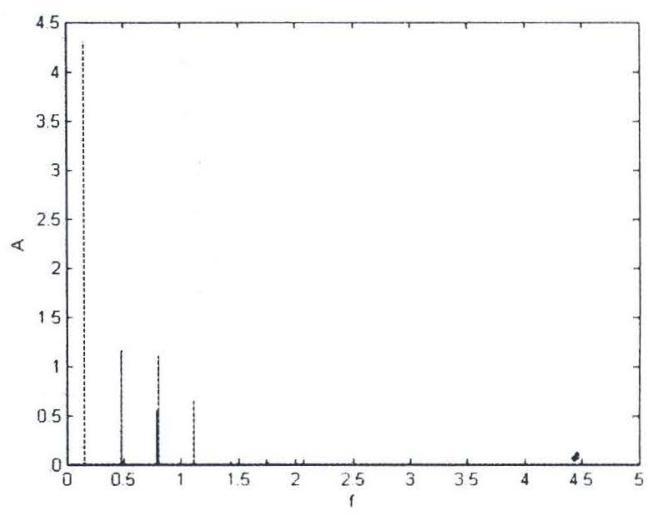

Fig. 9d. Frequency spectrum

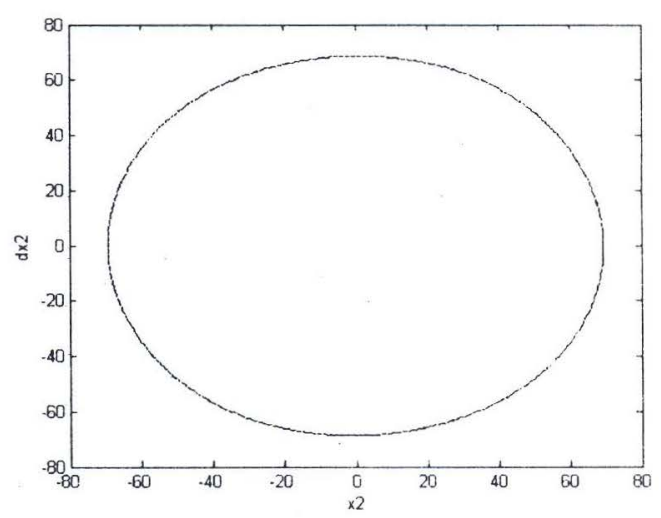

Fig. 9f. Phase orbit

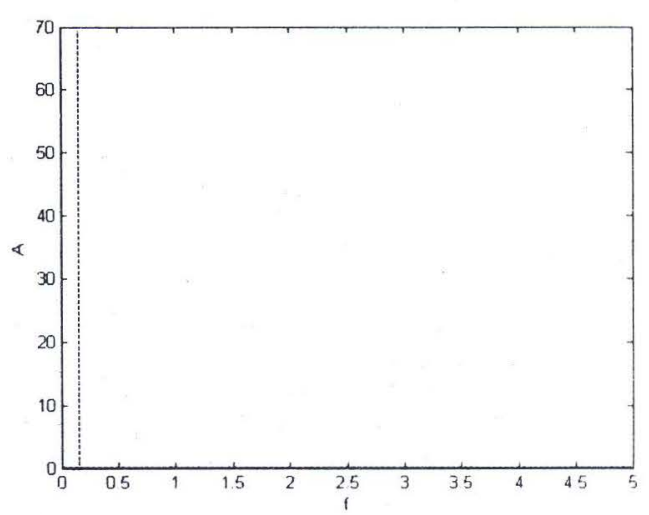

Fig. 9h. Frequency spectrum

3.4. Control force $\boldsymbol{B}_{1}=12.2, \boldsymbol{B}_{2}=2$ 


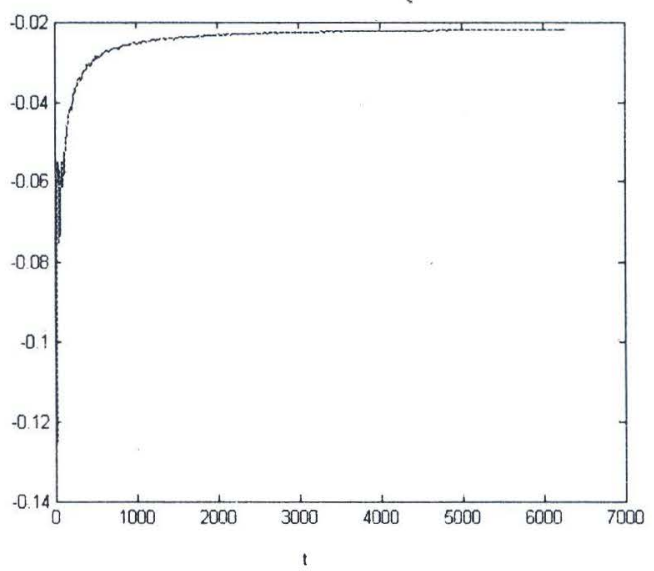

Fig. 9i. Lagest Lyapunov exponent

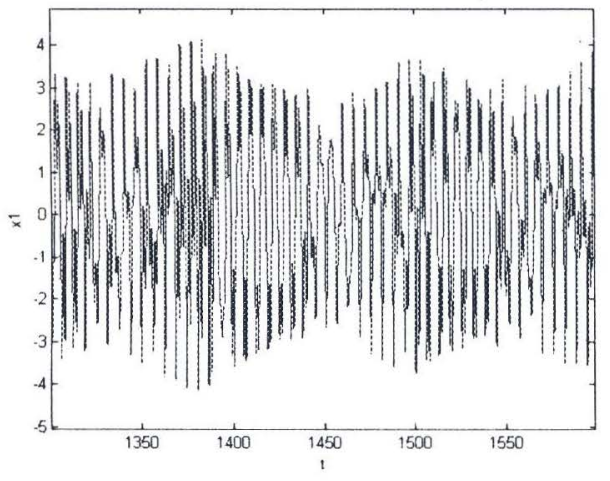

Fig. 10a. Displacement of $x_{1}$

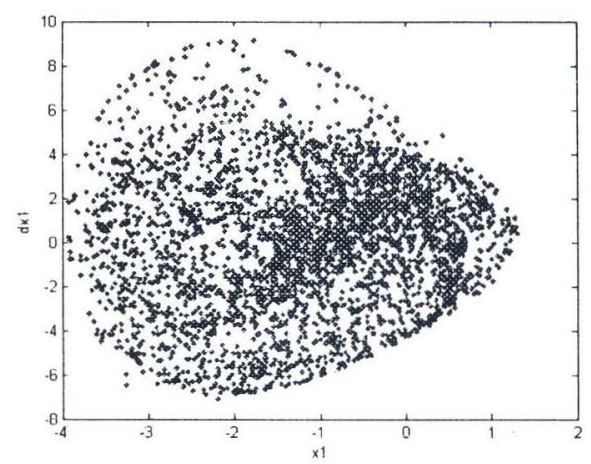

Fig. 10c. Poincare map

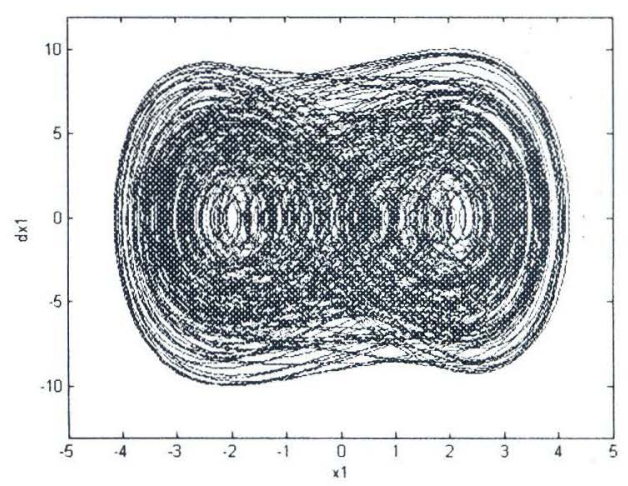

Fig. 10b. Phase orbit

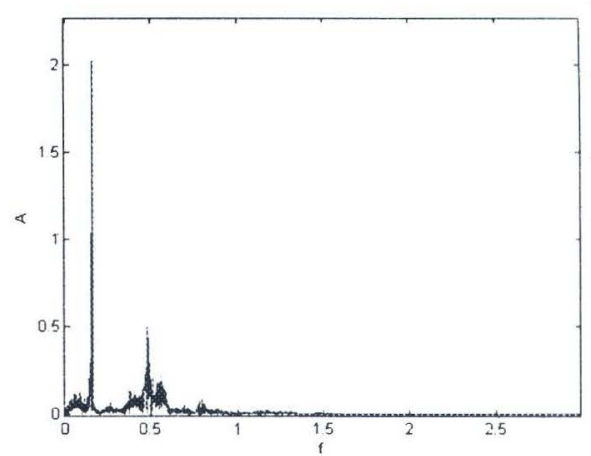

Fig. 10d. Frequency spectrum

The Figs. 10a-10h show the characteristics of chaos for $B_{1}=12.2, B_{2}=2$. The Figs. $10 \mathrm{a}$ and $10 \mathrm{e}$ present the displacement of $x_{1}$ and $x_{2}$. The trajectories in phase plane are 


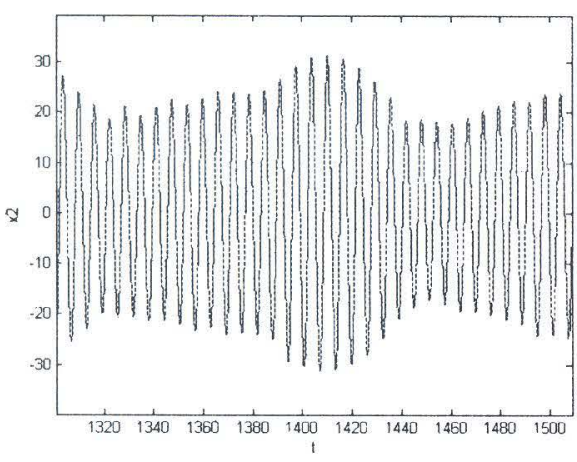

Fig. 10e. Displacement of $x_{2}$

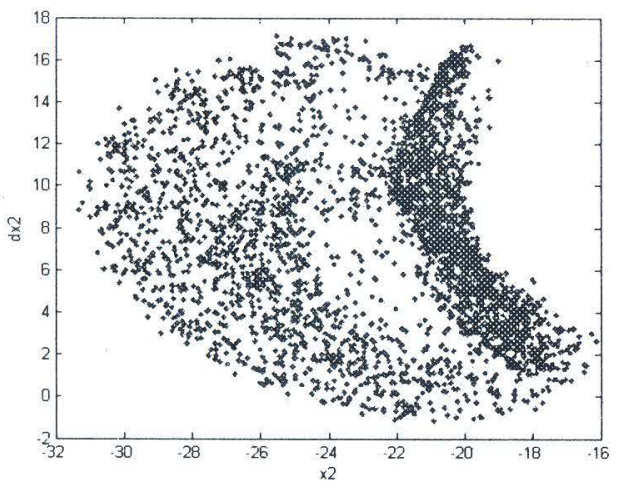

Fig. 10g. Poincare map

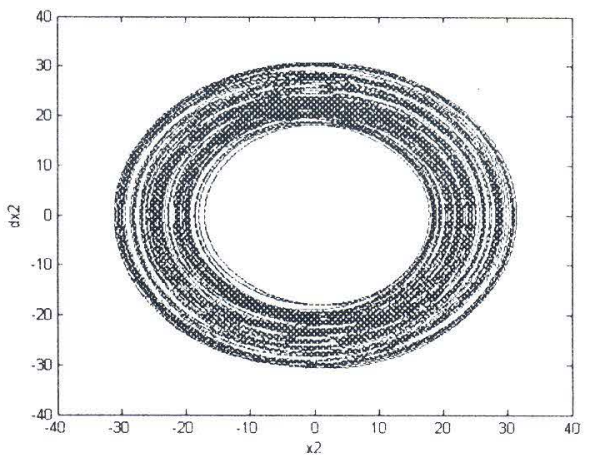

Fig. 10f. Phase orbit

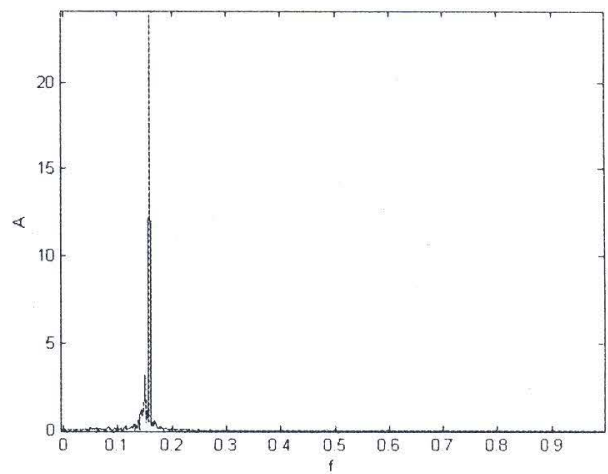

Fig. 10h. Frequency spectrum

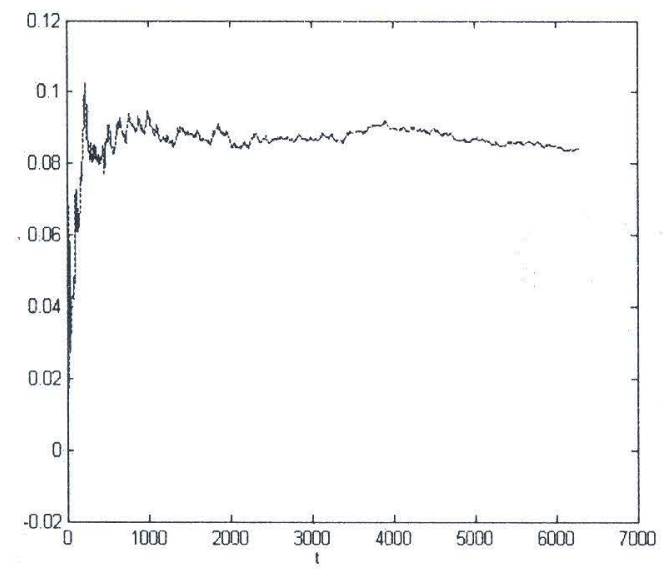

Fig. 10i. Lagest Lyapunov Exponents

shown in Figs. 10b and 10f. The Poincare maps are presented in Figs. 10c and 10g. Figs. $10 \mathrm{~d}$ and $10 \mathrm{~h}$ present the frequency spectrum. As it can be seen from the largest 
Lyapunov exponent map in Fig. 10i, the largest Lyapunov exponents for this case are always positive.

\section{BIFURCATION DIAGRAMS}

The bifurcation diagram is a modern technique used to analyze nonlinear systems. In a bifurcation diagram, dynamical behaviors may be viewed globally over a range of parameter values and it is possible to compare simultaneously different types of motions. Thus the bifurcation diagram provides a summary of essential dynamics and is therefore a useful tool for acquiring the overview.

Based on the numerical solution of motion equations, the Poincare map can be constructed by sampling the displacement and the velocity of the mass $m_{1}$ with a time $2 \pi / \Omega$. To show bifurcation diagrams in a plane, the Poincare maps have to be projected into the parameter $B_{i}$ axis. The bifurcation diagrams are presented by varying respectively the amplitude $B_{i}(\mathrm{i}=1,2)$ of the control forces for all other parameters fixed.

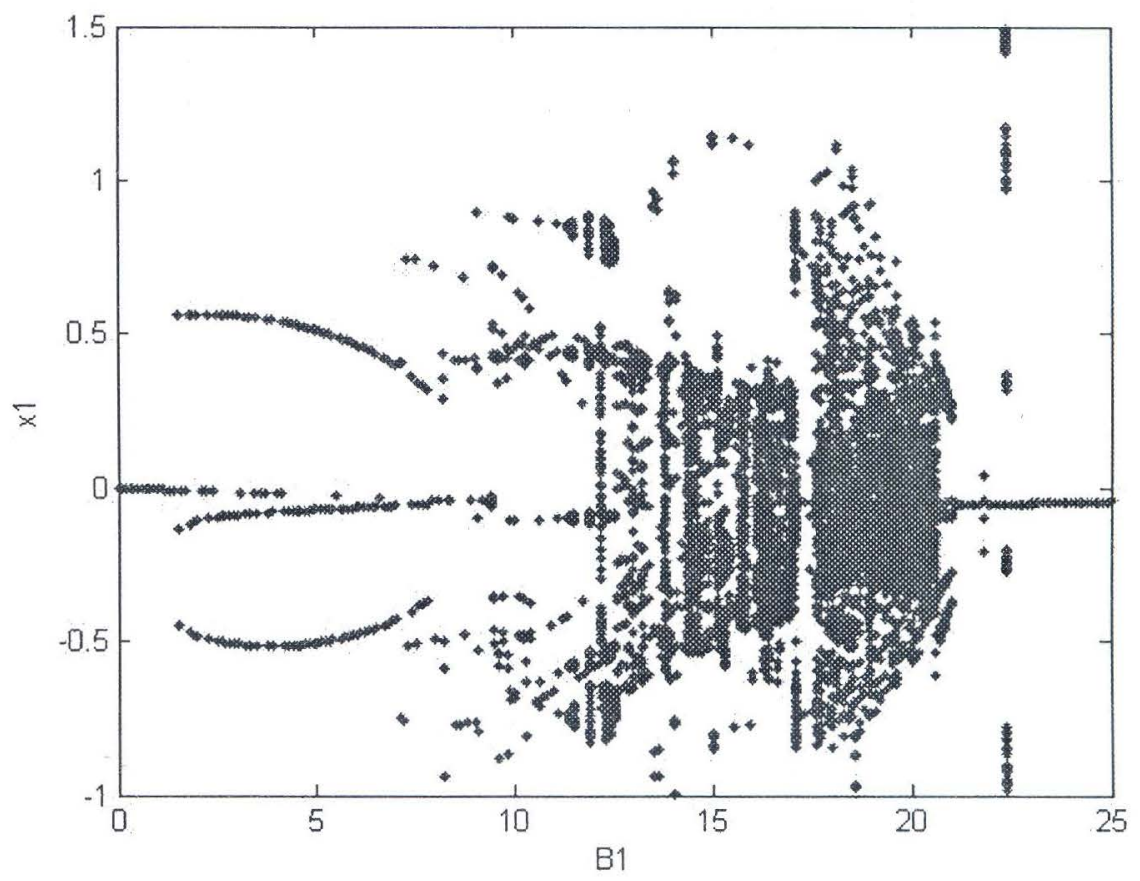

Fig. 11. Bifurcation diagram with $B_{2}=0 ; B_{1}=[0.25]$

The Fig. 11 is the bifurcation diagram via the changing amplitudes $B_{1}$ of the control force $B_{1} \cos \Omega t$. The Fig. 12 presents the bifurcation diagram via the changing amplitude $B_{2}$ of the control force $B_{2} \cos \Omega t$. In all cases, there have been obtained many interesting phenomena. For example in the neighborhood of chaos there exist regular and quasiperiodic solutions. Several values are given in the table $1[17,18]$. In the first column are the values of $B_{1}\left(B_{2}=0\right)$ and in the second the period multiplied by $T_{O}=2 \pi / \Omega$. Numerical calculations are made by the assumption that all initial conditions are zero. 
Table 1

\begin{tabular}{cccc}
\hline$B_{1}$ & period $^{*} T_{0}$ & $B_{1}$ & period $^{*} T_{0}$ \\
\hline 12.0 & 2 & 17.5 & 3 \\
12.1 & quasi-periodic & $17.6-20.3$ & chaos \\
$12.2-12.4$ & chaos & 20.5 & quasi-periodic \\
12.5 & 725 & 20.7 & 7 \\
12.6 & 5 & 21.0 & 1 \\
\hline
\end{tabular}

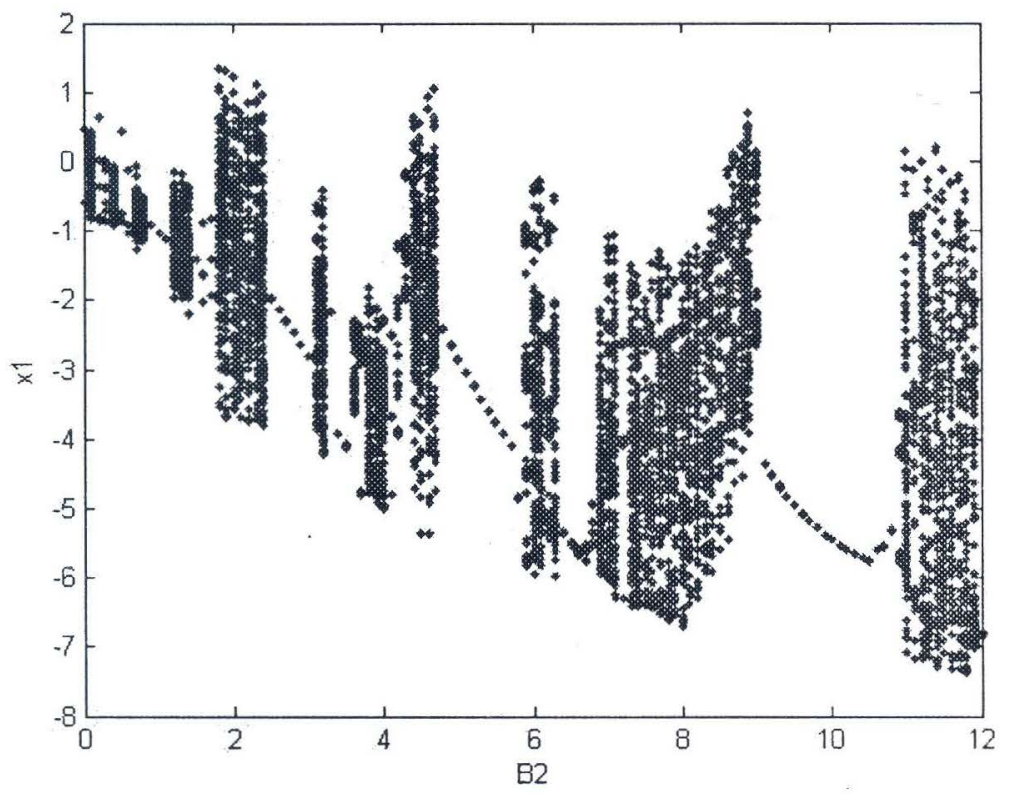

Fig. 12. Bifurcation diagram with $B_{1}=12 ; B_{2}=[0,12]$

Based on the numerical solution of motion equations one can obtain the following Table $2[18]$

Table 2

\begin{tabular}{|c|c|c|c|c|}
\hline $\mathrm{B}_{2}$ & 6 & 12 & 12.2 & 18 \\
\hline 0 & periodic & periodic & chaotic & chaotic \\
\hline 2 & chaotic & chaotic & chaotic & chaotic \\
\hline 5 & periodic & periodic & periodic & periodic \\
\hline
\end{tabular}




\section{CONCLUSIONS}

In this paper, the authors investigate the transition from regular periodic motion to chaotic behaviors in the two degrees of freedom Duffing system by changing amplitudes of the harmonic excitation forces. The Lagrange equations are applied to develop the differential equations of motion. Using the Software MATLAB the nonlinear dynamical behaviors of system are numerically investigated by means of the displacement, the Poincare map, the phase portrait, the frequency spectrum and the largest Lyapunov exponent. Bifurcation diagrams are presented to show the displacement and velocity projections of the Poincare maps changing respectively with the amplitudes of the excitation forces.

Acknowledgement. This paper is supported by the Vietnam Basic Research Program in Natural Science.

\section{REFERENCES}

1. F. C. Moon, Chaos Vibration (2.Edition), John Wiley and Sons, New Jersey 2004.

2. J. Guckenheimer and P. Holmes, Nonlinear Oscillations, Dynamical Systems and Bifurcation of Vector Fields, Springer, New York 1983.

3. J. M. T. Thompson, H. B. Stewart, Nonlinear Dynamics and Chaos (2. Edition), John Wiley and Sons, New York 2002.

4. T. Kapitaniak, Chaos for Engineers, Springer, Berlin 1998.

5. H. Troger and A. Steindl, Nonlinear Stability and Bifurcation Theory, Springer, Wien 1991.

6. S. H. Strogatz, Nonlinear Dynamics and Chaos, Addison-Wesley, Reading 1994.

7. J. Argyris, G. Faust, M. Haase, Die Erforschung des Chaos, Vieweg, Braunschweig/Wiesbaden 1995.

8. B. Vongxaya, Ordnung und Chaos bei nichtlinearen Schwingungen, Verlag Harri Deutsch, Frankfurt am Main 1995.

9. Nguyen Van Dao, Tran Kim Chi, Nguyen Dung, An introduction to Nonlinear Dynamics and Chaos (in Vietnamese), Vietnam National University Publishing House, Hanoi, 2005.

10. Nguyen Van Dao, Nguyen Van Dinh, Tran Kim Chi, Van der Pol's oscillator subjected to complicated excitations, Chaotic Phenomenon, Journal of Nonlinear Oscillations 4 (4) (2001) 500-527, Kiev.

11. Nguyen Van Dao, Tran Kim Chi, Nguyen Dung, Nonlinear dynamics and chaos. Proceedings of the sixth Vietnam Mathematical Conference, Vietnam National University Publishing House, Hanoi, 2002, pp.115-122.

12. Nguyen Van Dao, Tran Kim Chi, Nguyen Dung, Study of regular oscillations and chaotic phenomena in a strong nonlinear Mathieu oscillator, Proceedings of the National Conference on Engineering Mechanics, Vietnam National University Publishing House Hanoi 2001, pp.47-54.

13. Nguyen Van Dao, Tran Kim Chi, Nguyen Dung, Chaotic phenomenon in a nonlinear Mathieu oscillator, Proceedings of the seventh National Congress on Mechanics, Vietnam National University Publishing House, Hanoi 2002, pp.40-49.

14. Nguyen Van Dao, Nguyen Van Dinh, Tran Kim Chi, Van der Pol's oscillator under the parametric and forced excitations, Ukrainian Mathematical Journal, Special issue dedicated to Mitropolskii's $90^{\text {th }}$ anniversary, Kiev 2006.

15. Nguyen Van Dao, Nguyen Van Dinh, Tran Kim Chi, Nguyen Dung, Van der Pol's oscillator under the parametric excitation of second degree and external force, Proceedings of the National Conference on Engineering Mechanics and Automation, Bach Khoa Publishing House, Hanoi, 2006, pp.45-64.

16. Nguyen Van Dao, Nguyen Van Dinh, Tran Kim Chi, Nguyen Dung, An numerical approach of chaotic motion in a Duffing-Van der Pol oscillator, Internnational Conference on Nonlinear analysis and Engineering Mechanics Today, 11-14 Dec. 2006.

17. J. Szopa, The analysis of the two-degree-of-freedom chaotic system, ZAMM 71 (1991), 4, T78-T83.

18. Nguyen Hoang Duong, The Transition from Regular Periodic Vibrations to Chaotic Vibrations of some Mechanical Systems, Bachelor-Thesis, Hanoi University of Technology 2007 (in Vietnamese). 


\section{VỀ SỰ CHUYỄN ĐỔI TỮ TÍNH CHẤT CHUYỄN ĐỘNG CHÍNH QUI SANG TÍNH CHẤT CHUYỄN ĐộNG HỖN LOẠN TRONG Hệ ĐộNG LựC HAI BẬC Tự DO}

Chủ đề chính của bài báo này là nghiên cứu sự chuyển đổi từ chuyển động chính qui tuần hoàn sang chuyển động hỗn loạn trong một hệ động lực hai bậc tự do bằng cách thay đởi các tham số điều khiền. Áp dụng phương trình Lagrange loại hai thiết lập các phương trình vi phân chuyển động phi tuyến của hệ. Dựa trên cách giải bằng số các phương trình vi phân thường, ta có thể xác định được số mũ Liapunov, phổ tần số, bản đồ Poincare và đồ thị chuyển động theo thời gian. Từ đó dễ dàng nhận biết chuyển động hỗn loạn hay chinh qui (tuần hoàn hoặc hầu tuần hoàn). 